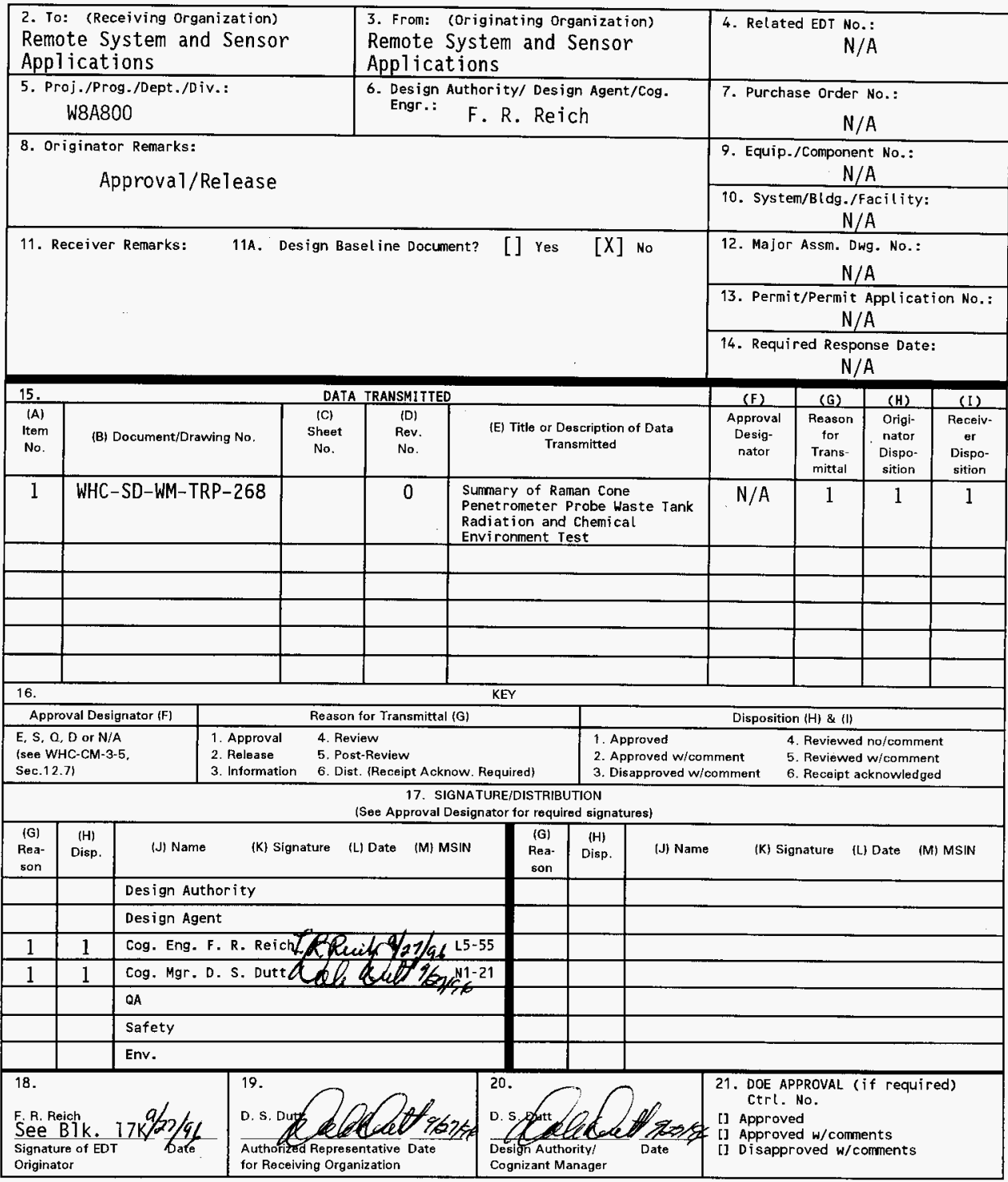




\title{
Summary of Raman Cone Penetrometer Probe Waste Tank Radiation and Chemical Environment Test
}

\author{
F. R. Reich \\ Westinghouse Hanford Company, Richland, WA 99352 \\ U.S. Department of Energy Contract DE-AC06-87RL10930
EDT/ECN: $618422 \quad$ UC: 2060
Org Code: 8A800 Charge Code: H2C3O
B\&R Code: EW4010000 Total Pages: 44

Key Words: Raman cone penetrometer probe, waste tank radiation, chemical environment test

Abstract: This report summarizes the results of testing Raman sapphire windows that were braze mounted into a mockup Raman probe head and stainless steel coupons in a simulated tank waste environment. The simulated environment was created by exposing sapphire window components, immersed in a tank simulant, in a gamma pit. This work was completed for the U.S. Department of Energy (DOE) Office of Environmental Management (EM-50) for Technical Task Proposal RL4-6-WT-21.

TRADEMARK DISCLAIMER. Reference herein to any specific commercial product, process, or service by trade name, trademark, manufacturer, or otherwise, does not necessarily constitute or imply its endorsement, recommendation, or favoring by the United states Govermment or any agency thereof or its contractors or subcontractors.

Printed in the United states of America. To obtain copies of this document, contact: WHC/BCS Document Control Services, P.O. Box 1970, Mailstop H6-08, Richland WA 99352, Phone (509) 372-2420: Fax (509) 376-4989.
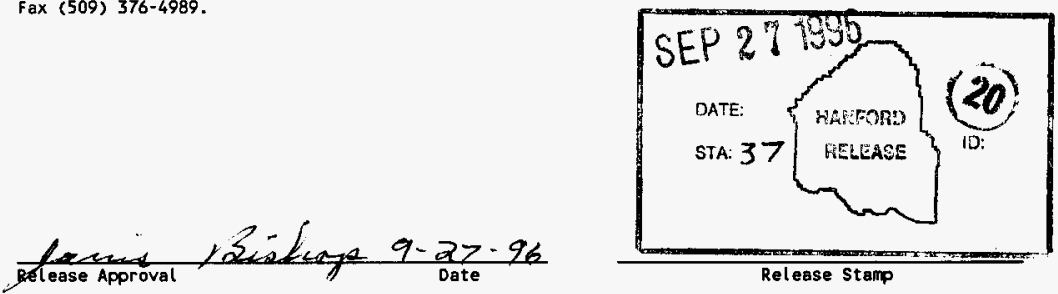


\section{Contents}

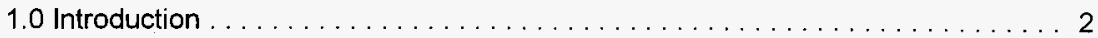

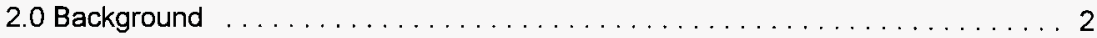

3.0 Waste Tank Simulated Test Environment $\ldots \ldots \ldots \ldots \ldots \ldots \ldots \ldots$

4.0 Tests and Test Components . . . . . . . . . . . . . . . . . . . 4

4.1 Test \#1 . . . . . . . . . . . . . . . . . . . . . . . 5

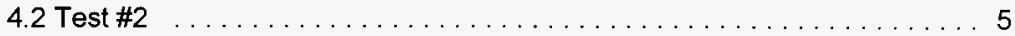

5.0 Simulated Environment Exposure and Documentation . . . . . . . . . . . 6

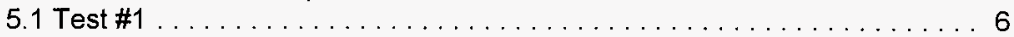

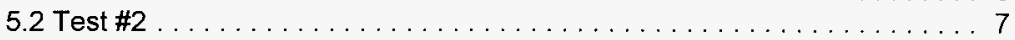

6.0 Test \#1 Results . . . . . . . . . . . . . . . . . . . . . . . . . 7

6.1 Optical Darkening - Test \#1 . . . . . . . . . . . . . . . 7

6.2 Test \#1 - Chemical/Radiation Performance of Diamond Coating . . . . . 8

6.3 Test \#1 - Indium/Silver Braze Performance . . . . . . . . . . . . . 8

6.3.1 Test \#1 - "48" Hour Chemical/Radiation Exposure . . . . . . . . 9

6.3.2 "17" Day Chemical/Radiation Exposure . . . . . . . . . . . . . 9

7.0 Test \#2 Results . . . . . . . . . . . . . . . . . . . . . . . . . . 10

7.2 Test \#2 - Braze ........................... 11

7.3 Test \#2 - Sapphire Window $\ldots \ldots \ldots \ldots \ldots \ldots \ldots \ldots \ldots \ldots \ldots \ldots \ldots$

8.0 Summary and Conclusions: $\ldots \ldots \ldots \ldots \ldots \ldots \ldots \ldots \ldots \ldots \ldots$

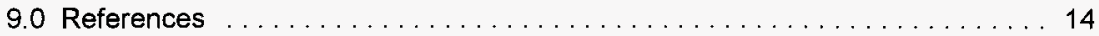

APPENDIX A - Raman Spectroscopic Cone Penetrometer . . . . . . . . . . . A A-1

APPENDIX B - Cobalt-60 Gamma Pit Irradiation Facility $\ldots \ldots \ldots \ldots \ldots$ B-1 
WHC-SD-WM-TRP-268, Rev. 0

\subsection{Introduction}

This report summarizes the results of testing Raman sapphire windows that were braze mounted into a mockup Raman probe head and stainless steel coupons in a simulated tank waste environment. The simulated environment was created by exposing sapphire window components, immersed in a tank simulant, in a gamma pit. This work was completed for the U.S. Department of Energy (DOE) Office of Environmental Management (EM-50) for Technical Task Proposal RL4-6-WT-21.

The parameters of the simulated environment were chosen to represent some of the harshest chemical and radiation levels anticipated in an actual Hanford waste tank deployment of the cone penetrometer. The survival of the Raman sapphire window and its brazed construction in this simulated environment will demonstrate that this brazed sapphire window probe design would survive deployment in a Hanford waste tank.

The high level wastes in Hanford's underground tanks are currently characterized by physically removing core samples and then completing conventional chemical analyses in hot cell laboratory facilities. The U.S. Department of Energy (DOE), Environmental Management division (EM-50) is providing resources for the development of in situ characterization systems for deployment in these tanks. Under the guidance of the Tank Focus Area (TFA), the Lawrence Livermore National Labs (LLNL) is developing a Raman system specifically for deployment in a tank with a cone penetrometer system (Technical Task Proposal SF26WT21). This probe must be capable of handling the harsh radioactive and caustic environment of the tank as well as satisfying the tank operational and safety criteria.

The LLNL Raman probe optical system uses radiation resistant optical fibers and optical components (lenses, mirrors and filters). The probe contains a sapphire window that will come in direct contact with tank waste as the cone penetrometer is pushed through a tank waste. Prior deployments of aluminum oxide (not sapphire) based substrates in tank wastes, had shown potential degradation of the "aluminum oxide" based components from the harsh chemical properties of the tank wastes. Although the actual degradation was never validated, it was believed that any aluminum oxide based material, such as the cone penetrometer's Raman sapphire window, would similarly degrade. The loss of the window during in-tank deployment would compromise the operation of the Raman probe and potentially impact the safety of the in-tank deployment.

\subsection{Background}

Nuclear waste by-products from Hanford Site weapon production missions are stored in a number of large single and double shell underground storage tanks. These high level 
WHC-SD-WM-TRP-268, Rev. 0

wastes generally consist of mixtures of hazardous chemicals and radionuclides typically found as layered salt cake, sludge, and supernatant liquids.

A cone penetrometer system with a Raman probe provides a method to access the waste constituents in the Hanford Site underground storage tanks through riser penetrations as indicated in Figure 1. LLNL has designed a Raman probe using fiber optics that fits into a cone penetrometer rod with a sapphire optical window on the side of the rod. The cone penetrometer system will push this probe into the waste, allowing Raman data to be recorded as the probe is moved down toward the bottom of the tank. As this rod moves through the waste, Raman information will be recorded from the waste. One of the bounding design parameters for the cone penetrometer is a push force on the cone penetrometer rod of 40 tons of pressure.

The Raman probe window must be capable of handling the deployment pressure, the abrasion of the wastes, and the caustic, radioactive waste environment without serious impacts on the Raman spectroscopy data. In addition, some wastes generate toxic or potentially flammable gases and thus, equipment in a waste tank must meet the safety requirements for operation in a Class 1, Division 1, Group B (Hydrogen) environment All of the probe's internal optical components, such as the fiber optic cable, filters, lenses and prism will be exposed to high radiation flux, but will be protected from the caustic environment by the probe's sealed window. However, the sapphire window, in the probe will be in direct contact with the tank waste.

The Raman probe head uses a sapphire window that is brazed into a stainless steel fixture attached to the cone penetrometer rod. The braze, which is a mixture of indium and silver, forms a chemical and pressure resistant physical seal around the sapphire window and also provides a mechanical buffer between the sapphire and stainless steel mount.

\subsection{Waste Tank Simulated Test Environment}

The chemical and radiation environment for the simulated testing was based on previous work that identified tank farm environments for deployment systems that included the Light Duty Utility Arm (LDUA) and a cone penetrometer system (Mailhot, 1994 and Philipp, 1994). The key tank environmental parameters from these earlier studies are summarized in Appendix A. Based on this environmental data and a review of initial tanks that the cone penetrometer might be deployed in, the test parameters shown in Table I was identified.

The two major elements of concern with the chemical bath are the caustic level $(\mathrm{pH})$ and the nitrite and nitrate levels. The concentrations of these were specifically set (see 
Appendix A) to represent an upper level bounding case for chemical harshness of tank wastes. Actual tank wastes are not expected to have this level of chemical contents, but could approach them. The nitrate/nitrite constituents have been identified as some of the major elements in the corrosion of metallic materials.

The target dose rate for the test, shown in Table I, was $600 \mathrm{R} /$ hour which places the test environment at the upper boundary of what is actually expected in most of Hanford's waste tanks. The radiation environment for the test was provided by the gamma pit facility in the Hanford 3730 Building ( 300 Area) that is operated by the Pacific Northwest National Labs (PNNL). This testing used Tube 35A which has the radiation profile shown in Appendix $B$.

The test fixture consisted of polyethylene bottle (wide mouth jar) inside a stainless steel canister which had a lifting bail for attaching a cable that was used to lower and raise the canister in the gamma pit tube. The elevation in the tube was set by placing a fixed length "spacer" in the tube before lowering the test canister. Measurements on the canister showed that loose components and coupons with mounted sapphire windows in the bottom of the canister were about 0.5 inches above the spacer platform, while the sapphire window in the Raman mockup probe was about 2.0 inches above this surface. Just prior to placement within the gamma pit, the Raman cone penetrometer components were placed into the chemical bath. Therefore, the chemical exposure times match very closely the radiation exposure time (within a 10-15 minute time interval).

\subsection{Tests and Test Components}

All of optical components in the tests were furnished by LLNL and represent the actual components that would be used with the Raman cone penetrometer probe for in situ deployment.

Two separate exposure tests were completed; Test \#1 and Test \#2. Test \#1 was completed in two parts with an interim component examination after the first 48 hours of exposure. The examination after the initial 48 hours of exposure provided confidence to continue and complete the planned 17 days of total exposure. This interim examination was prompted by a general lack of experience with the Raman probe components in radiation and chemical environments. The principal issue was potential darkening after the 48 hours of exposure. However, after no visible damage or darkening was found, the components the test was resumed until the equivalent of a 17 day total exposure was accumulated. 
WHC-SD-WM-TRP-268, Rev. 0

Test \#2 was completed after it was discovered that the braze on the diamond coated window which was in the cone penetrometer mockup head, contained pinholes that leaked during the final 15 days of exposure in the gamma pit. LLNL then revised the braze mixture and the procedures in the brazing operation for the samples in Test \#2. As shown by the data below, these modifications were successful.

\subsection{Test \#1}

The Raman optical components that were exposed in Test \#1 are listed in Table II. During the irradiation exposure, the loose optical components (filters, lenses, prism and an unmounted sapphire window) were placed in the bottom of the outer stainless steel canister where they experienced radiation but not the chemical exposure. The diamond coated sapphire window was mounted in the Raman mockup probe.

Both of the Test \#1 mounted sapphire windows were brazed into their stainless steel fixtures using an indium-silver braze alloy of $10 \%$ silver and $90 \%$ indium. As indicated in table II, only one of the sapphire windows was diamond coated. The diamond coating was originally designed to provide additional abrasion resistance for the sapphire window. However, LLNL deleted it from the design after it was discovered that the coating had very poor adhesion properties. The coating didn't adhere to any of the test fixtures surfaces (sapphire window, braze, or stainless steel mount surfaces) and could be literally be "wiped" off any of the surfaces with mild rubbing.

Figure 2 shows the actual radiation dose levels that the test components experienced for both the 48 hour and 17 day exposures. The range in the dose rates is a result of the different elevations of the components in Tube 35A. The gamma dose profile for Tube 35A is shown in appendix $B$.

\subsection{Test \#2}

As indicated above, Test \#2 was completed after it was discovered that the braze around the sapphire window in the Raman mockup probe contained pinholes that leaked while it was immersed in the test simulant. This leakage was visually evidenced by the accumulation of liquid and dried crystals on the inner surface of the sapphire window. The leak was later confirmed by LLNL with helium leak testing.

The Test \#2 components consisted of three braze mounted sapphire windows as indicated in Table III. These windows were mounted using a 3\% silver and $97 \%$ indium braze mixture, using a process that had better temperature control during heat-up and better thermal control during cool-down then that used for Test \#1. Two of the windows were brazed into stainless steel coupons and experienced chemical exposures on both sides of the window. The third window was mounted in the Raman mockup probe, 
WHC-SD-WM-TRP-268, Rev. 0

similar to the diamond coated window in Test \#1, with chemical exposure only on the outer surface of the window.

Test \#2 was exposed to radiation in the 236,000 to $291,000 \mathrm{R}$ range over an approximate 17 day exposure time period. The range in the dose rates is a the different elevations within Tube $35 \mathrm{~A}$ and from slight aging of the cobalt sources in the gamma pit (the dose profile for Tube 35A is shown in appendix $B$ ).

\subsection{Simulated Environment Exposure and Documentation}

\subsection{Test \#1}

Test \#1 was completed in two stages, as indicated in Table I, because of the lack of prior knowledge of the sensitivity of the Raman probe components with the chemical and radiation environments. The following exposure and documentation sequence was used in Test \#1:

1. Prior to exposure testing, the sapphire window and braze surfaces were photographed with $100 \times$ magnification. This data provided base-line documentation from which any chemical or radiation induced changes in the surfaces of the components could be qualitatively assessed. The location of these photographs for both of the sapphire window test fixtures is shown in Figures 3 and 4.

2. After the initial 48 hours of exposure were completed, the canister was retrieved, optical components removed from the bath and washed with distilled water. The sapphire window and braze surfaces were re-photographed at approximately the same physical locations. No visual evidence of darkening or chemical damage were found. The components were then placed back in the chemical bath and inserted into the gamma pit for an additional 15 days of exposure.

3. After an additional 15 days of exposure was completed, the optical components were removed and washed with distilled water. After visually examining the loose optical components for signs of darkening, they were immediately sent to LLNL. An aliquot of the chemical bath from within the test container was also sent to LLNL for analysis. The presence of indium or silver, not originally in the chemical bath makeup, would indicate that some etching of the braze had taken place.

4. The sapphire window and braze surfaces were again photographed at the approximately the same surface locations using $100 \times$ mag. (magnification). Selected surface areas of the loose sapphire window and the braze mounted sapphire windows were also "photographed" with a Scanning Electron Microscope(SEM). The windows 
were then returned to LLNL where helium leak detection methods were used to validate leakage from the braze pinholes. As indicated below, some of the pinhole locations correlated with surface features found on the sapphire window surface.

\subsection{Test \#2}

1. Prior to exposure testing, selected areas of the braze for all three sapphire windows were photographed at $100 \times$ mag. The location of these photographs for the three Test \#2 sapphire windows are in Figures 5,6, and 7. Select surfaces areas on all three of the sapphire windows were also SEM photographed. An atomic force microscope (AFM) was used to scan surfaces of the two coupon mounted sapphire windows (the window mounted in the Raman mockup probe fixture would not fit into the micro-probe system so AFM data could not be obtained from its sapphire window). The AFM is similar to a conventional contact probe profilometer. However, the resolution of the AFM is on the order of an Angstrom. After this documentation was completed, the components were placed in the simulant bath and lowered into the gamma pit.

2. After 17 days of exposure, the canister was retrieved from the gamma pit and the sapphire window components removed and washed with distilled water. The sapphire window braze areas were again photographed at the approximately the same surface locations as in 1 . above at $100 \times$ mag.

After a more thorough cleaning, select surfaces areas on all three of the sapphire windows were SEM photographed. Select surfaces on the two coupon mounted sapphire windows were scanned with an AFM probe. This completed the final documentation of the braze areas and sapphire windows.

6.0 Test \#1 Results

\subsection{Optical Darkening - Test \#1}

As indicated in Figure 2, an exposure time of 48 hours resulted in a gamma dose of $36,400 \mathrm{R}$ (Rad) of $\mathrm{Co}^{60}$ radiation for the loose" optical components and sapphire window in the stainless steel coupon. The sapphire window in the Raman probe mockup received a dose of about $29,200 R$. The visually examination showed no sign of optical darkening in any of these "loose" or mounted components. The coating makeup of the optical filters precluded visible observations of any darkening.

After the 17 day exposure, all of the components made from BK-7 glass showed visible evidence of optical darkening (an assessment of filter darkening was again precluded by the filters coatings). However, none of the quartz components showed significant 
darkening. No attempts were made to quantify the level of darkening. Immediately after removal from the gamma pit, the optical components (lenses, filters and prism) were sent, via an over-night shipper, to LLNL for their analyses.

This exposure test shows evidence that there will be some loss of optical transmission if exposure levels approach the 300,000 R levels and if fused silica (BK-7) glass is used. Excessive darkening will decrease the Raman signals which will in turn increase noise and require longer exposure times to obtain good Raman spectra. The darkening would also impact the use of Raman (in a system with no internal calibration)in quantitative assessments. The darkening is due to radiation damage in the glass and coating materials. Some of the darkening will be temporary and will anneal or clear with time and temperature. However, part of the anticipated radiation damage will be permanent and accumulates with total exposure time.

\subsection{Test \#1 - Chemical/Radiation Performance of Diamond Coating}

Figure 8 shows $100 x$ mag. photos of sapphire window, diamond coating before chemical/radiation exposure and after the 17 day exposure. These photographs are representative of what was observed around the whole sapphire window/braze interface area. The curved feature is the edge of the sapphire window.

The upper two pictures, in Figure 8, show the surface with back-illumination, while the lower two photographs were taken with front-illuminated. The left-column are surfaces prior to chemical/radiation exposure, while the right-column show surfaces after the 17 day exposure test was completed. The diamond coating was not strongly bonded to the sapphire window, especially at the edge of the window. There were large areas of the coating that had flaked off even before completing the chemical/radiation exposure tests were initiated. Additional flaking was probably due to the cleaning that was needed to remove residual chemicals from the surfaces.

The tests showed no evidence that the flaking was accelerated by the chemical/radiation exposure. Since SEM photographs were not recorded for any of the diamond coated sapphire, it is not known if the coating had any impact on the chemical performance of the sapphire surface.

\subsection{Test \#1 - Indium/Silver Braze Performance}

As indicated in Figures 3 and 4 , a number of braze surface areas were examined on both the diamond coated window and the un-coated window stainless steel assemblies. The "figure" labels shown in Figures 3 and 4 correspond to the photographs shown below. 
Figures 9 and 10 show the $100 x$ pictures of the diamond coated window assembly while Figure 11 shows a representative area of the braze interface for the un-coated sapphire window.

The width of the braze for the diamond coated assembly was in the 0.15-0.2 mm range while the braze width for the un-coated assembly was larger, $0.25-0.35 \mathrm{~mm}$ range. The braze rings did not exhibit a uniform surface roughness between samples. The braze also had a varying roughness around the circumference of each window. The uncoated sapphire braze area appeared to have an overall smoother surface than braze areas on the diamond coated assembly.

The small dark features in Figures 9.10 and 12 are braze pinholes. As indicated below, some of the pinholes in the diamond coated assembly (Figures 9 and 10) penetrated the full depth of the braze and were responsible for leakage found after the 17 day chemical/radiation test. The sealing features of the un-coated assembly were not tested after their chemical/radiation exposure was completed.

\subsubsection{Test \#1 - "48" Hour Chemical/Radiation Exposure}

The main feature observed as a result of the 48 hour chemical/radiation exposure appears to be a slight increase in surface dullness of the un-coated braze surface. This is especially evident in Figure 11. The source of this slight dulling is suspected to be from chemical etching with a subsequent increase in the optical roughness of the indium/silver braze surfaces. The diamond coating appears to have protected the braze from any physical changes, as evidenced by the lack of changes in Figures 9 and 10 (compare the left and right upper two pictures in each figure). Neither the un-coated or the diamond coated braze surfaces showed any large changes that would indicate a significant loss of material due to chemical etching. This is substantiated by the braze areas in Figure 11, which retained its surface smoothness.

The visual examination of the components showed no signs of optical darkening after 48 hours where a dose of 29,200-36,400 R was accumulated.

\subsection{2 "17" Day Chemical/Radiation Exposure}

After the 17 day time period, the diamond coating showed no evidence of surface changes (compare the upper-left and lower-right pictures of Figures 9 and 10 from either the chemical bath or the radiation. The detailed surface features (scratches, etc.) were no altered, which indicates that there are no large surfaces changes in the braze due to etching or loss of material to the chemical bath. It would appear that the diamond coating did offer some chemical protection to the braze surface. 
The un-coated braze surface appears to have suffered some small chemical etching damage. However, the depth of the changes are very small and the amount of materials removed is also very small as was confirmed by LLNL from their analysis of the chemical bath sampled after the test was completed. Only a very small amount of indium and no silver was detected in the etchant using mass spectroscopy techniques. The conclusion is that the chemicals and radiation had a negligible impact on the braze as result of chemical etching.

The diamond coated sapphire window was mounted in a "mockup" cone penetrometer fixture which is sealed with "O-rings". The visual examination after the 17 day exposure showed the presence of white crystals around the braze ring. The investigation indicated that this was chemical bath crystals and that the leakage was not due to any of the fixture "O-ring" seals. After documenting with photographs, the assembly was sent to LLNL where a leak test confirmed a pinhole leak in the braze. One of the leaking pinholes is shown in Figure 9; the inverted " $v$ " structure is apparently the leaking pinhole. The small dark spot in Figure 10 is a non-leaking pinhole. Figure 12 shows a similar pin-hole feature for the braze surface of the un-coated sapphire window coupon. No testing was completed to confirm the leakage status of this pinhole.

\subsection{Test \#2 Results}

For Test \#2, an exposure time of 17 days resulted in the sapphire windows braze mounted in stainless steel coupons receiving a gamma dose of about 291,000 $R$ while the sapphire window in the Raman probe mockup received about $236,000 \mathrm{R}$. An inspection immediately after removal from the gamma pit and chemical bath revealed no visible signs of radiation damage (darkening of the sapphire window), chemical etching to either the sapphire window, braze or stainless steel mounts.

Figures 13 and 14 show an overall view of the sapphire window and surrounding braze interface areas for the " $\mathrm{T}$ " and the "O" test samples. The dark hole is the inner diameter hole of the mount. The braze land is visible as a "shiny" ring around this dark hole. The dull outer circle in Figure 13 is braze material on the stainless steel mount.

The dimensions for the coupons and their sapphire windows are shown in Table IV. Coupons " $\mathrm{N}$ " and "O" had approximately the same dimensions. Coupon " $\mathrm{T}$ ", which was the window mount for the Raman mockup probe, has a slightly larger mounting hole in the stainless steel mount (producing a wider braze land around the window) and had its window mounted "flush" with the mount surface. This test sample was also sealed so that the chemicals only contacted the outer window surface. Coupons " $\mathrm{N}$ " and " $\mathrm{O}$ " were open so chemicals made contact with both sides of the window. 
The $97 \%$ indium $+3 \%$ silver braze material was found to be very soft and could be easily scratched or marred (the material can be significantly indented and scratched with a finger nail).

\subsection{Test \#2 - Braze}

Figures 15,16 and 17 each show two areas of the window/braze interface for each of the three test coupons. The locations for these $100 x$ mag. photos on each of the test coupons are shown in Figures 5,6 and 7 respectively. For Figures 15, 16 and 17, the upper row of photos shows the surfaces prior to the chemical/radiation exposure, while the lower row are the same surfaces after the 17 days of exposure were completed.

Since the braze was very soft, only a minimum of wiping was done during the cleaning of the coupon surfaces. Every attempt was made to retain surface features, especially on the braze, for re-locating areas in the post-test photos. The dark feature in the left column of Figure 16 is a chip in the edge of the sapphire window. The lower right-hand photo shows some of the surface contamination from the chemical bath that was not removed during cleaning. Figure 17 shows additional evidence of incomplete cleaning of the sapphire window surface.

Each of the brazed areas contained very small crack and crevice or void like features, similar to that shown in Figure 12. However, it is surmised that these features didn't penetrate through the braze as no evidence of leakage was found in the post-test examination of coupon "T". The large braze land on the inner surface of the window probably contributes significantly to this sealing.

In comparing the pre- and post-exposure braze surface areas, the most striking feature is a loss of surface brightness. This is consistent with Test \#1 results and is due to a slight etching of the braze from the chemical bath. The loss of material is especially evident in the right column of Figure 15 where some of the braze material attached to the window surface (upper photo) is not present after the test (lower photo). This also can be seen in the right column of Figure 17.

The conclusion is that an insignificant amount of braze material will be removed by the tank waste. If the braze contains no through pinholes, this will not compromise the sealing properties of the window. This window design can be safely deployed in the Hanford tank wastes with a cone penetrometer system. 
WHC-SD-WM-TRP-268, Rev. 0

\subsection{Test \#2 - Sapphire Window}

Figures 18, 19 and 20 show Scanning Electron Microscope (SEM) photographs of select sapphire window surfaces for coupons "T", "N", and "O" respectively. The lefthand column in each Figure shows an SEM of the surface before chemical/radiation exposure, while the right column shows post-test SEM photos. Each row shows decreasing magnification ( 1 micron to approximately 50 micron as noted in each Figure's caption). The SEM system used a method involving water vapor rather than a gold coating to induce surface conductivity which is necessary to obtain the SEM data. A goid coating was avoided because of the need to have an unaltered sapphire surface next to the simulant chemicals.

The SEM photos in Figure 18 for the "T" coupon sample, shows a similar surface textures between the before and after test photos. This indicates that the overall sapphire surface was probably not impacted by the chemicals.

In Figures 19 and 20, the surface features in the right-hand columns (after exposure) are from residual surface contamination that wasn't removed during cleaning. This is confirmed by the Atomic Force Microscope (AFM) data shown below.

The line structures in these SEM photos are micro-scratches that were not polished out in the sapphire window surfaces. Etching should have slightly rounded the scratch edges, but this not detectable in this SEM data. In fact, Figure 20 shows very similar line features in the before (left column) and after-exposure (right column) SEM data.

Figures 21 and 22 show the results of Atomic Force Microscope (AFM) for selected sapphire window surfaces for test coupons " $\mathrm{O}$ " and " $\mathrm{N}$ ". The fixture of coupon "T" was too long and wouldn't fit into the AFM system. The left column of Figures 21 and 22 is pre-exposure data while the right-column is after exposure data. The vertical range in the upper row of AFM photos 900-1000 angstroms. The lower row of AFM photos have a $100-200$ angstrom range.

The residual surface contamination is visible in these AFM photos as large spikes on the normally relatively smooth surface (specifically see Figures $21 a, 21 b$, and $22 b$. These are not pitts as Figure 21a shows a line scratch which produces a surface change in direction opposite of the surface contamination.

The sapphire windows in the test coupons were optical grade with smooth polished surfaces. This is evident from the left column of AFM photos in Figures 21 and 22. These AFM photos are very representative of what was found over the total sapphire window surface. From the AFM data, it was estimated that the sapphire windows had a surface roughness value ( $\mathrm{rms}$ ) the 5-15 angstrom range. A similar analysis of these 
surfaces after the 17 day exposure test indicated no change in the surface roughness. This would indicate that the sapphire surfaces in the chemical bath were basically unaltered by the chemicals. Any chemical etching would have upset the surface texture and probably would have produced some surface pitting. The AFM photos in Figures 21 and 22 are representative of the AFM data from areas sampled over the total surface of both the " $\mathrm{N}$ " and "O" coupon sapphire windows. No pitting was found and the post-exposure surface roughness was also in the 5-15 angstrom (rms) range. There also no changes in the profiles of scratches for the pre- and post-exposure AFM data.

The lack of pitting and retention of surface structure (scratch sidewalls) and continuity of surface texture indicate that the sapphire windows were not affected (at least to the degree that the SEM and AFM photos are capable of resolving) by the simulant bath or the gamma radiation. Thus, a sapphire window would survive an in-tank deployment without compromising the operation or safety of a cone penetrometer Raman probe.

\subsection{Summary and Conclusions:}

Raman cone penetrometer, sapphire windows components that were brazed into stainless steel mounts were subjected to two chemical and radiation exposure tests, both well beyond what is anticipated for a waste tank cone penetrometer campaign.

After 17 days of exposure $\left(277,200-309,700 \mathrm{R} \mathrm{Co}^{60}\right.$ gamma) in a 3-4 molar waste simulant (2-3 molar nitrate and nitrite content), no evidence of damage or changes in the optical or physical properties of the sapphire window or its braze materials were observed.

Although a slight surface etching of the braze occurred (evidenced by surface dulling), the amount of braze material removed (estimated by LLNL to be less than $1 \%$ ) would not impact in-tank operation or safety envelope of a cone penetrometer Raman probe.

Scanning Electron Microscope (SEM) and Atomic Force Microscope (AFM) data from the sapphire windows (resolution in the angstrom range) showed no evidence of microscopic changes to damage to sapphire window surfaces. The sapphire window's surface texture, scratch profiles, and rms roughness estimates were unchanged after a 17 day exposure in a simulated waste environment. The sapphire window surfaces showed no signs of pitting or rounding of scratch profiles in the AFM photos.

The window leakage in the Test \#1 Raman probe head mockup was due to pinholes in the braze material. The presence of leaking pinholes was confirmed LLNL for these test coupons. A second test campaign, Test \#2, was completed using LLNL components 
with an improved braze and brazing operation. No leakage or compromising of the braze seal occurred in this second test.

Based on these tests, the sapphire window and braze design is adequate to support the safe deployment of a Raman probe in any of Hanford's waste tanks. The simulated testing indicated that a cone penetrometer can withstand at least a 17 day residency in most of Hanford's underground tanks, which is well beyond current and anticipated tank exposure parameters (time and chemical/radiation levels). Fused silica components replaced with quartz and sapphire would be even more rugged than the current LLNL Raman probe design used in these two exposure tests.

\subsection{References}

1. Mailhot, R.B., January 28,1994 , Environmental and Interface Design Basis for an LDUA Raman Spectroscopy End Effector, WHC-SD-TD-DB-001, Rev 0,

2. Philipp, B.G., February 22, 1994, Environmental Requirements for Hanford Deployable, Cone Penetrometer Raman Spectroscopy Fiber Optic Probes, WHC-SDTD-RPT-008, Rev 0, Westinghouse Hanford Company, Richland, Washington. 
Table I

Chemical/Radiation Exposure Test Parameters

Radiation: Target: $600 \mathrm{R} / \mathrm{hr}^{(1)}$

Test \#1 actual: 605-754 R/hr

Test \#2 actual: 575-710 R/hr

Test Exposures:

- Test \#1:

48 hours

17 days (same chemical bath and radiation level but for an additional 15 days)

Radiation Dose:

48 hour Target: $28,800 \mathrm{R}$

Actual: $29,200-36,400 \mathrm{R}$

17 day Target: $300,000 \mathrm{R}$

- Test \#2:

Actual: $277,200-309,700 \mathrm{R}$

17 days

Radiation Dose:

Target: $300,000 \mathrm{R}$

Actual: $236,000-291,000 \mathrm{R}$

Chemical

Sodium Nitrate

Sodium Nitrite

Sodium Carbonate

Sodium Hydroxide

Aluminum Nitrate

(nonhydrate)

Water

(1) R - Rad
Concentration

(wt \%)
Molarity

2.0

3.9

0.8

10

4.3

10

0.5 
WHC-SD-WM-TRP-268, Rev. 0

\section{Table II}

\section{Test \#1 Cone Penetrometer Components}

Mounted Sapphire Windows ${ }^{(1)}$ :

1. Diamond coated sapphire window brazed ${ }^{(2)}$ in mockup cone penetrometer fixture.

2. Un-coated sapphire window braze ${ }^{(2)}$ mounted in stainless steel coupon.

Un-mounted Optical Components: $:^{(3)}$

3. Un-coated sapphire window.

4. Laser collimating and Raman scattered light collection lens.

5. $90^{\circ}$ right angle prism.

6. Laser band-pass filter(silica Raman suppression filter) and laser notch filter.

(1)Random cut sapphire with unknown crystal orientations.

(2) LLNL $10 \%$ silver, $90 \%$ indium braze alloy.

(3) Both quartz and fused silica (BK-7) components tested.

Table III

Test \#2 Cone Penetrometer Components

Mounted Sapphire Windows ${ }^{(1)}$.

1. Sapphire window brazed ${ }^{(2)}$ in mockup cone penetrometer fixture.

2. Sapphire window braze ${ }^{(2)}$ mounted in stainless steel coupon.

3. Sapphire window braze ${ }^{(2)}$ mounted in stainless steel coupon.

(1) Random cut sapphire with unknown crystal orientations.

(2) LLNL 3\% silver, $97 \%$ indium braze alloy. 
WHC-SD-WM-TRP-268, Rev. 0

Table IV. Test Coupon Dimensions for Test \#2

\begin{tabular}{|c|c|c|c|}
\hline Parameter: & "T" & "O" & "N" \\
\hline Window Diameter: & $6.2 \mathrm{~mm}$ & $6.2 \mathrm{~mm}$ & $6.2 \mathrm{~mm}$ \\
\hline $\begin{array}{l}\text { Stainless Steel Mount: } \\
\text { Outer hole diameter: }\end{array}$ & $7.2 \mathrm{~mm}$ & $7.0 \mathrm{~mm}$ & $7.0 \mathrm{~mm}$ \\
\hline Inner hole diameter: & $5.6 \mathrm{~mm}$ & $5.6 \mathrm{~mm}$ & $5.6 \mathrm{~mm}$ \\
\hline Braze surface width: & $2.5 \mathrm{~mm}$ & $2.0 \mathrm{~mm}$ & $2.0 \mathrm{~mm}$ \\
\hline Window depression: & $0.0 \mathrm{~mm}$ & $-0.25 \mathrm{~mm}$ & $-0.27 \mathrm{~mm}$ \\
\hline
\end{tabular}


WHC-SD-WM-TRP-268, Rev. 0

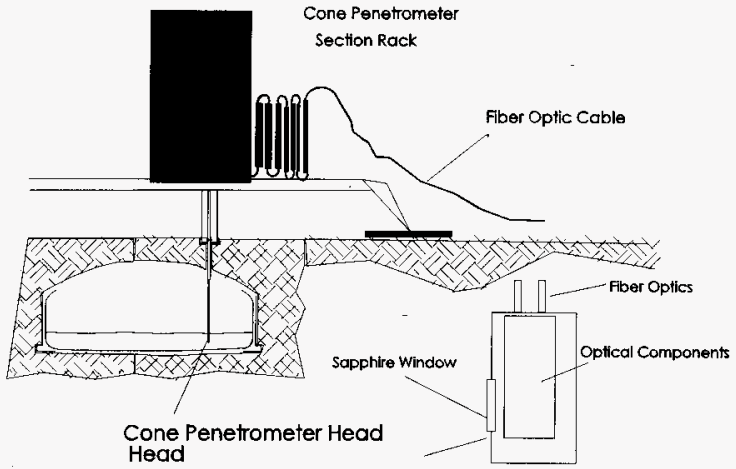

Figure 1. Cone Penetrometer System with Raman

Fiber Optic Probe deployed in an underground waste tank. The inset shows the major components of the Raman probe head.

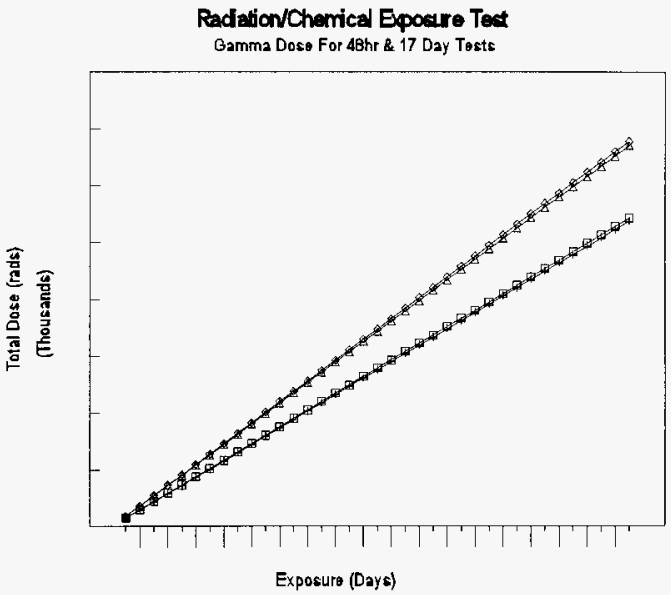

Figure 2. Gamma dose levels (Cobalt-60) for 48 hours and for 17 days of exposure in tube $35 \mathrm{~A}$ of the 3730 Gamma Pit facility. The dose rate was dependent in the elevation within tube $35 \mathrm{~A}$, as indicated in Appendix A. 
WHC-SD-WM-TRP-268, Rev. 0

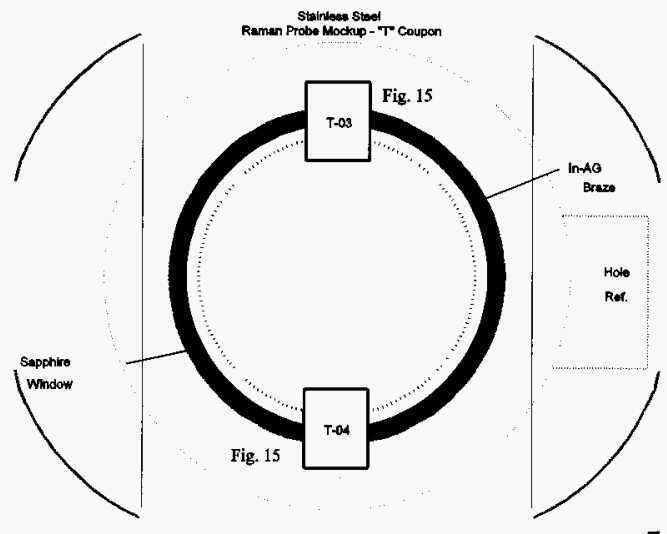

Figure 5. Raman probe mockup window for Test \#2 showing positions of $100 \mathrm{x}$ photographs. The sapphire window was diamond coated and mounted using a $97 \%$ indium $+3 \%$ silver braze.

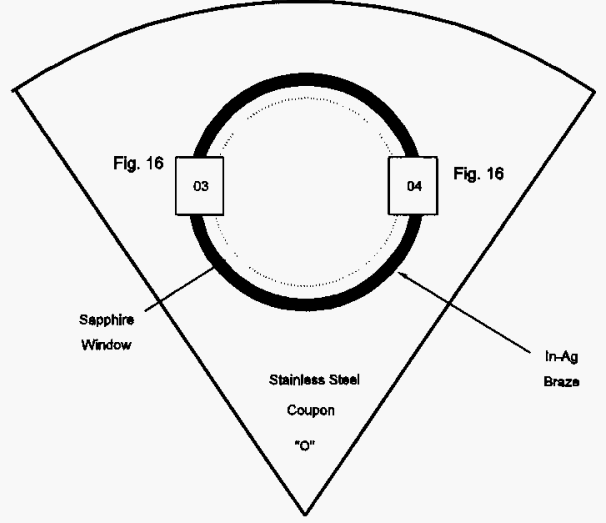

Figure 6. Sapphire window coupon "o"

mounted in stainless steel coupon for Test \#2 showing positions for $100 x$ photography. The window was mounted using a $97 \%$ indium and $3 \%$ silver braze. 
WHC-SD-WM-TRP-268, Rev. 0

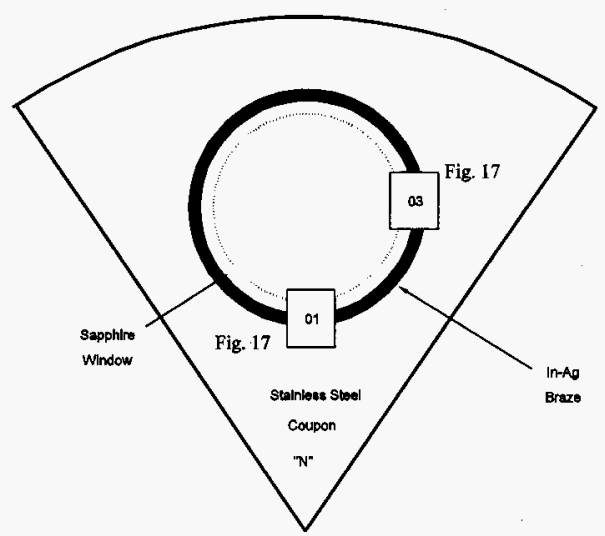

Figure 7. Sapphire window coupon "N" mounted in stainless steel coupon for Test \#2 showing positions for $100 x$ photography. The window was mounted using a $97 \%$ indium and $3 \%$ silver braze. 


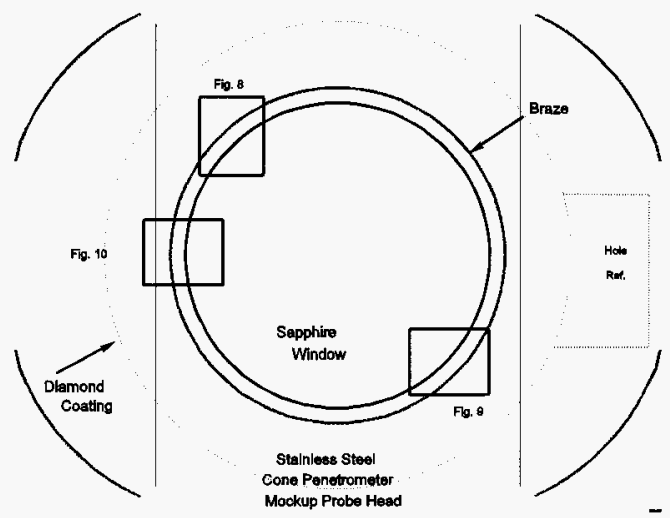

Figure 3. Raman probe mockup window for Test \#1 showing positions of $100 \mathrm{x}$ photographs. The sapphire window was diamond coated and mounted using a $90 \%$ indium $+10 \%$ silver braze.

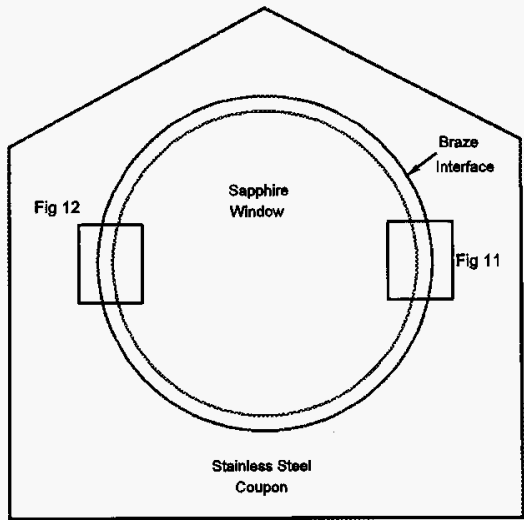

Figure 4. Sapphire window mounted in stainless steel coupon for Test \#1 showing positions of $100 x$ photography. The sapphire window was un-coated and mounted using a $90 \%$ indium $+10 \%$ silver braze. 
WHC-SD-WM-TRP-268, Rev. 0

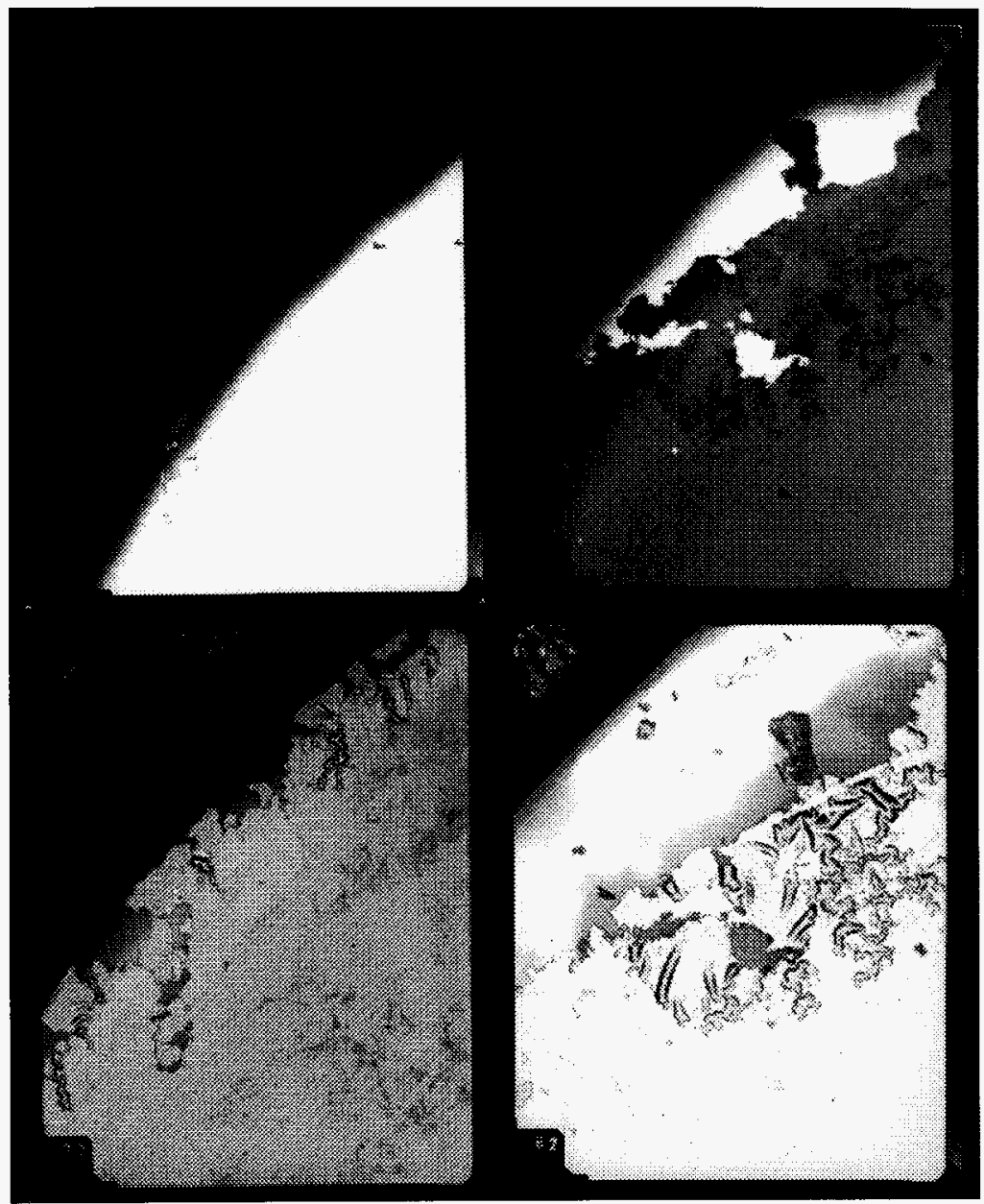

Figure 8. Diamond coated sapphire surface. Clockwise from upperleft: a. Pre-chemical/radiation exposure, back-illumination, b. Post-17 days of exposure, back-illumination, c. Post-17 days of exposure, front-illumination, d. Pre-chemical/radiation exposure, front-illumination. 
WHC-SD-WM-TRP-268, Rev. 0

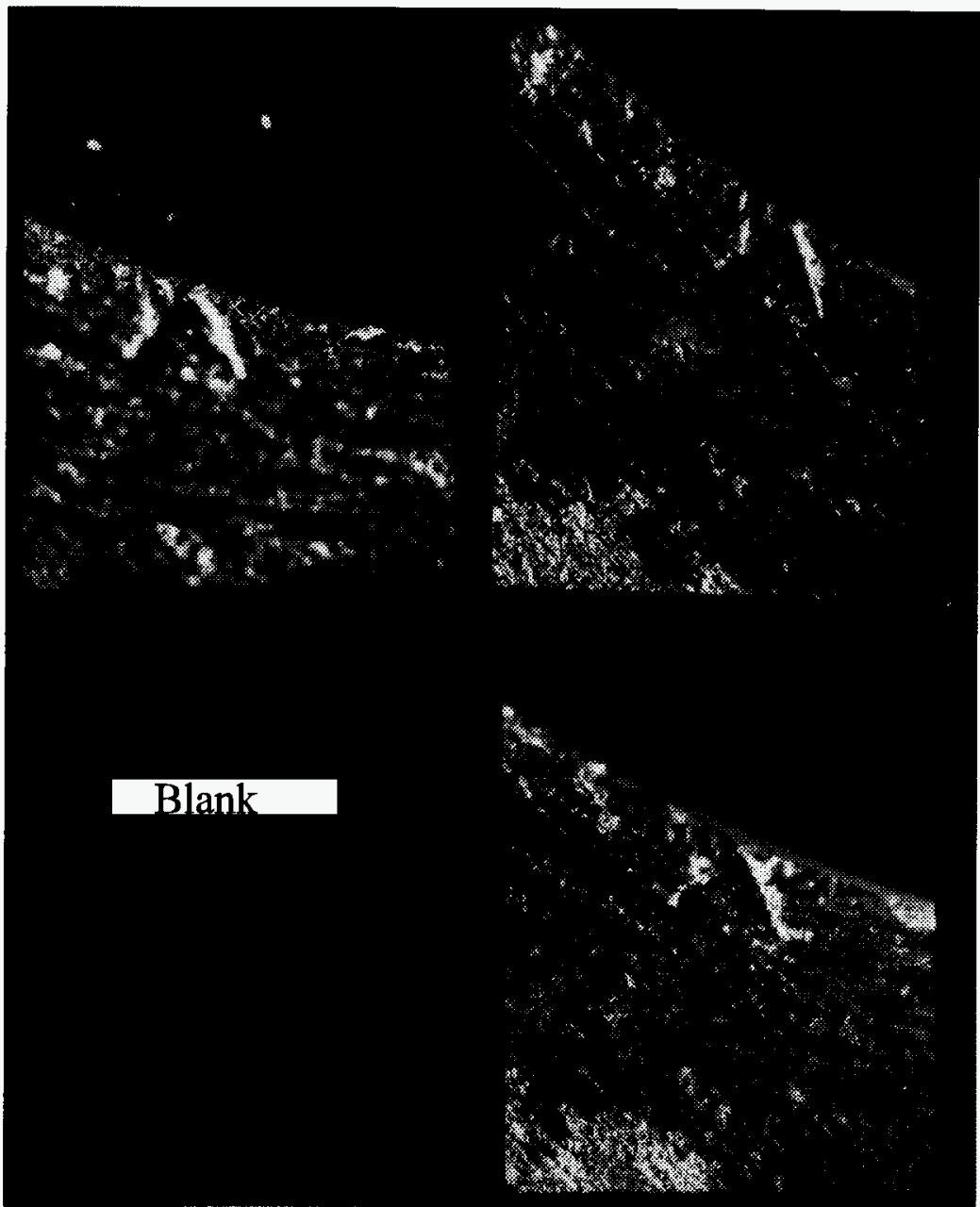

Figure 9. Diamond coated sapphire window showing the braze interface. Clock-wise from upper-left: a. base-line, prechemical/radiation exposure, b. after 48 hour exposure, and $c$. after 17 day exposure. All pictures are $100 x$ magnification. 


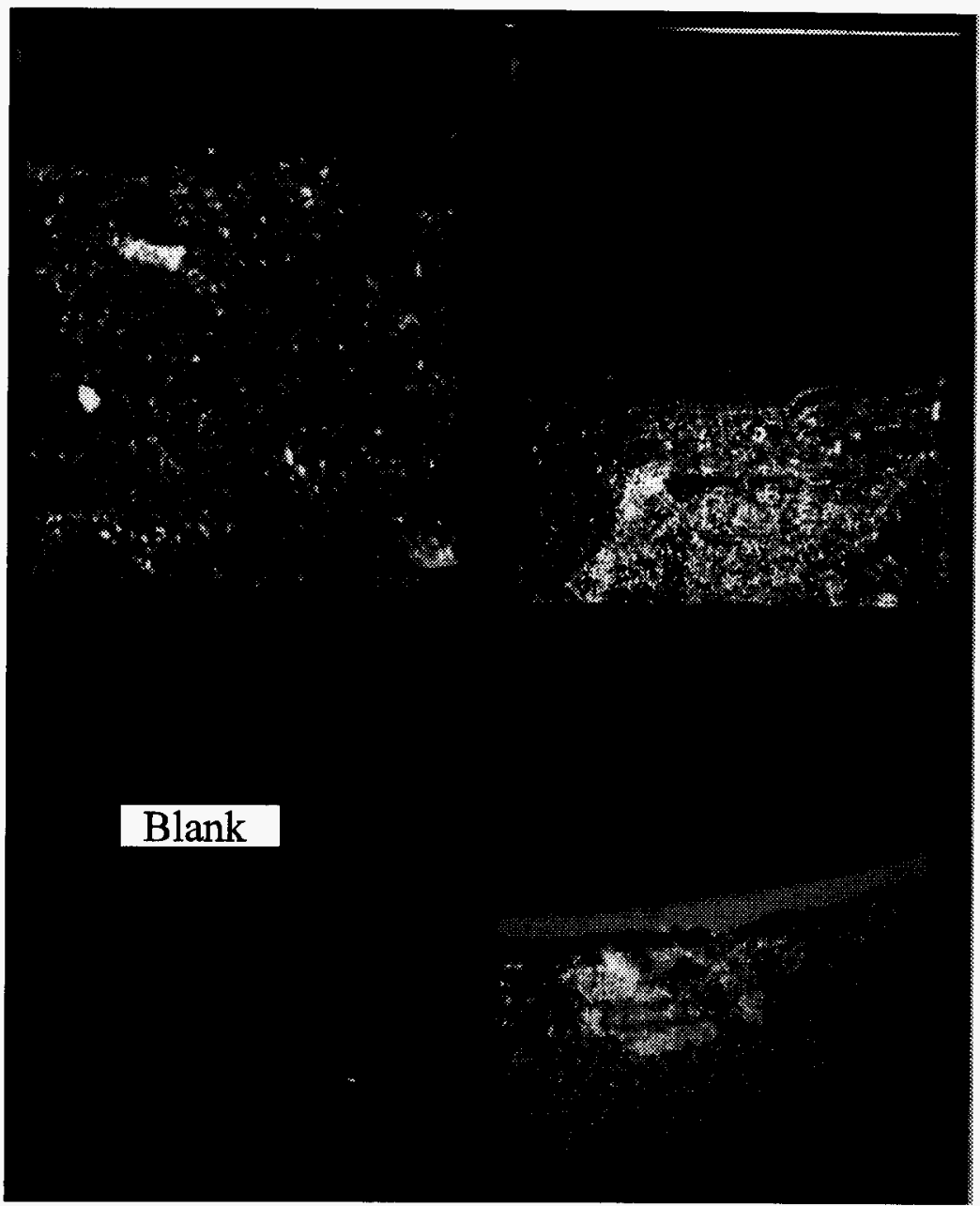

Figure 10. Diamond coated sapphire window showing the braze interface. Clock-wise from upper-left: a. Pre-chemical/radiation exposure, b. Post-48 hour exposure, and $c$. Post-17 day exposure. All pictures are $100 x$ magnification. 


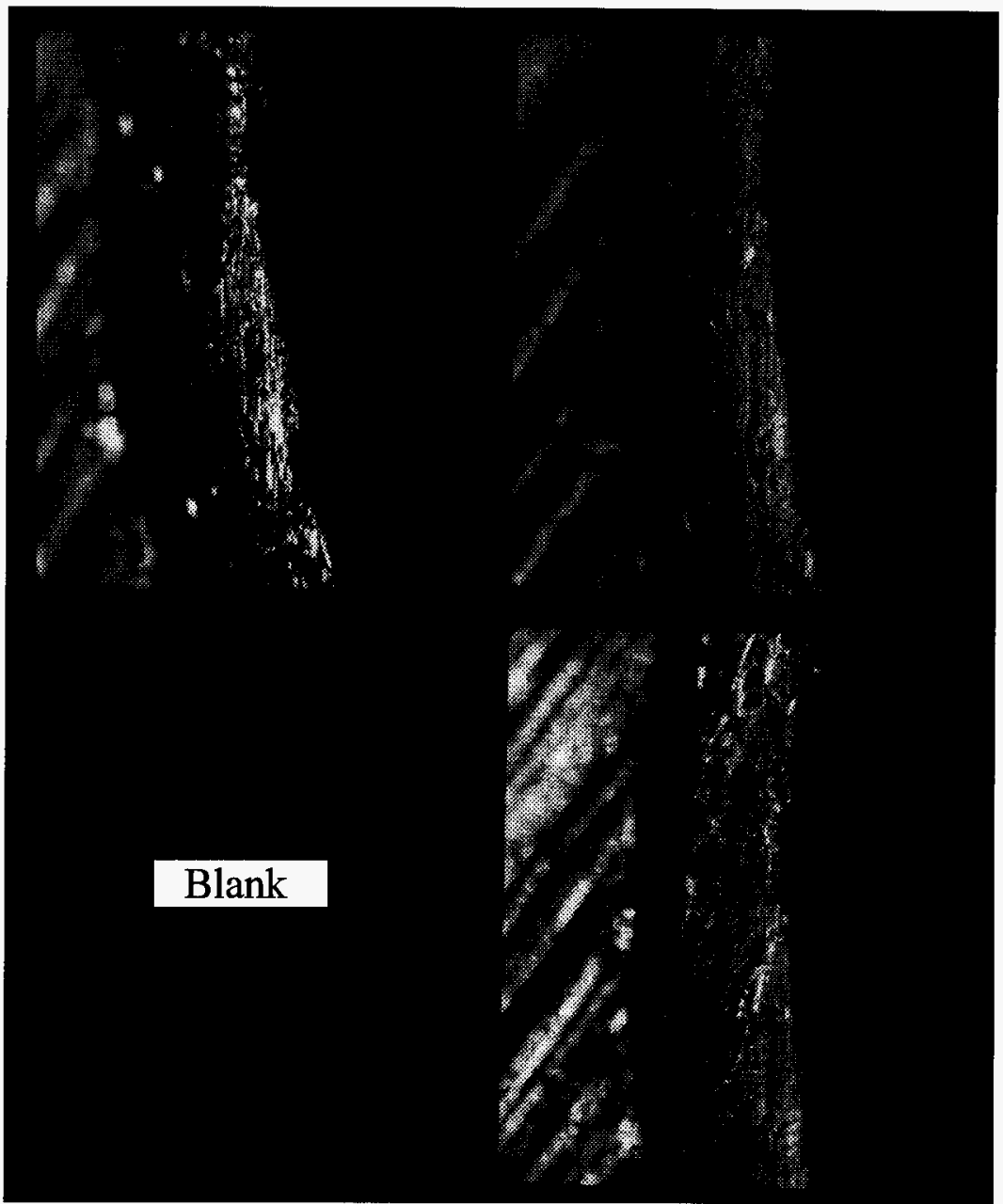

Figure 11. Un-coated sapphire window showing the braze interface. Clock-wise from upper-left: a. Pre-chemical/radiation exposure, b. Post-48 hour exposure, and $c$. Post-17 day exposure. All pictures are 100x magnification. 
WHC-SD-WM-TRP-268, Rev. 0

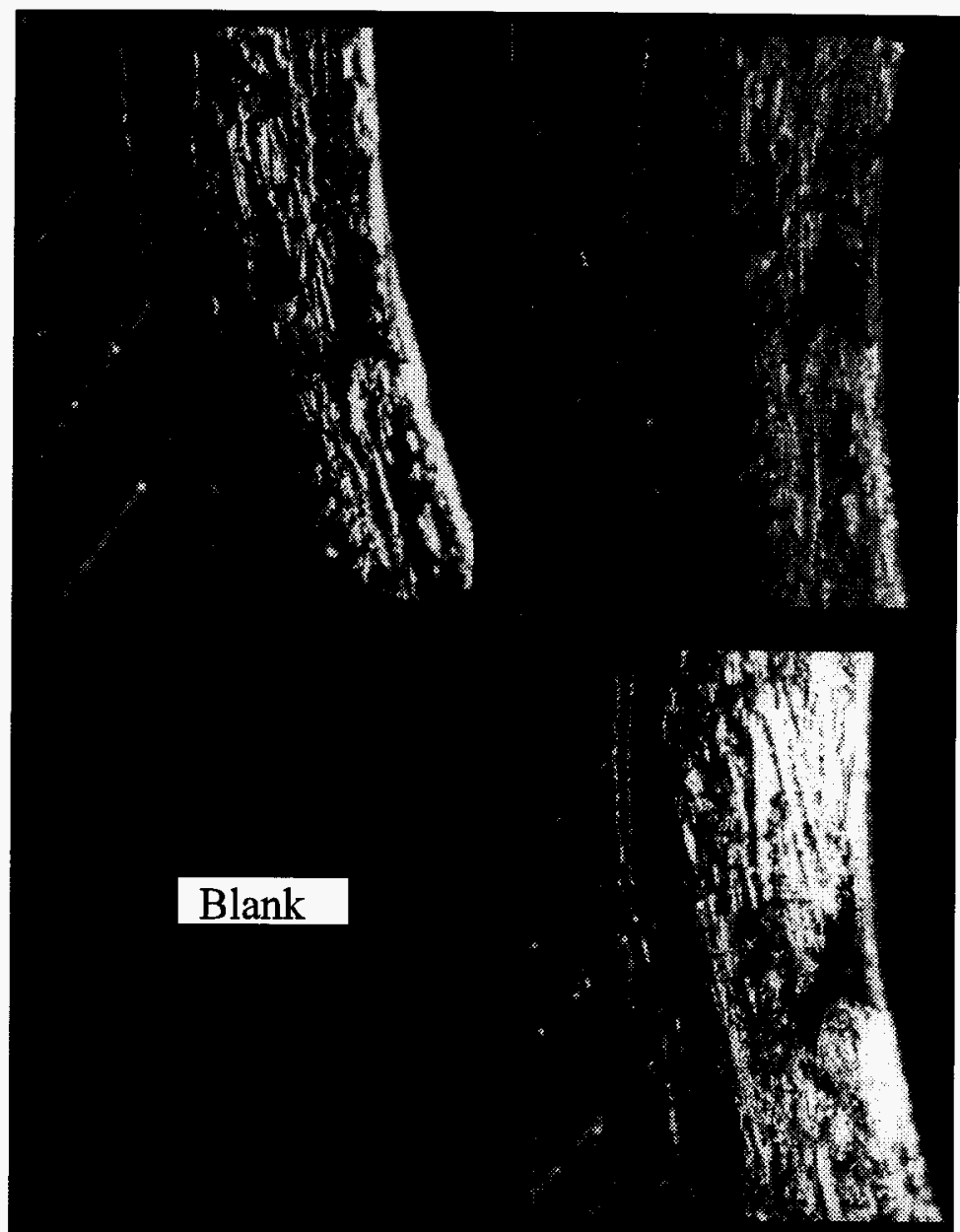

Figure 12. Un-coated sapphire window showing the braze interface. Clock-wise from upper-left: a. Pre-chemical/radiation exposure, b. Post-48 hour exposure, and $c$. Post-17 day exposure. All pictures are $100 x$ magnification. The dark feature is a pin-hole or crevice of unknown depth in the braze material. 
WHC-SD-WM-TRP-268, Rev. 0

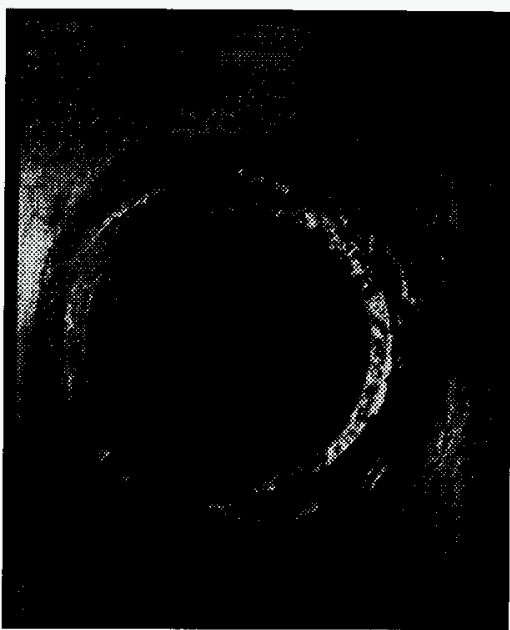

Figure 13. Test \#2 coupon " $T$ ": Sapphire window brazed into Raman probe mockup mount, - top view.

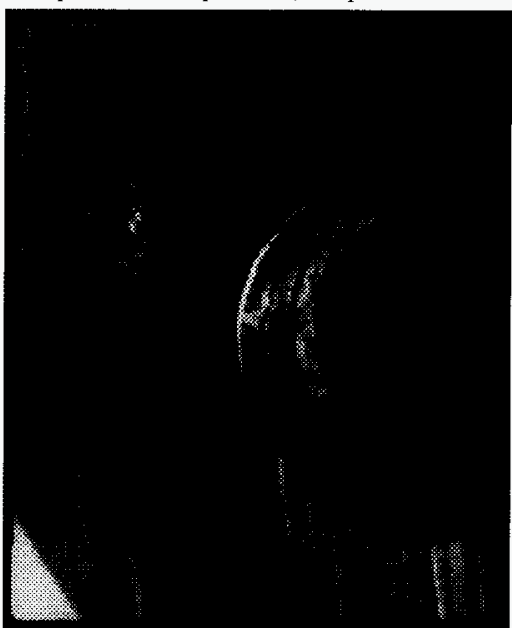

Figure 14. Test \#2 coupon "O": Sapphire window brazed into stainless steel coupon, - 45 degree view. 
WHC-SD-WM-TRP-268, Rev. 0

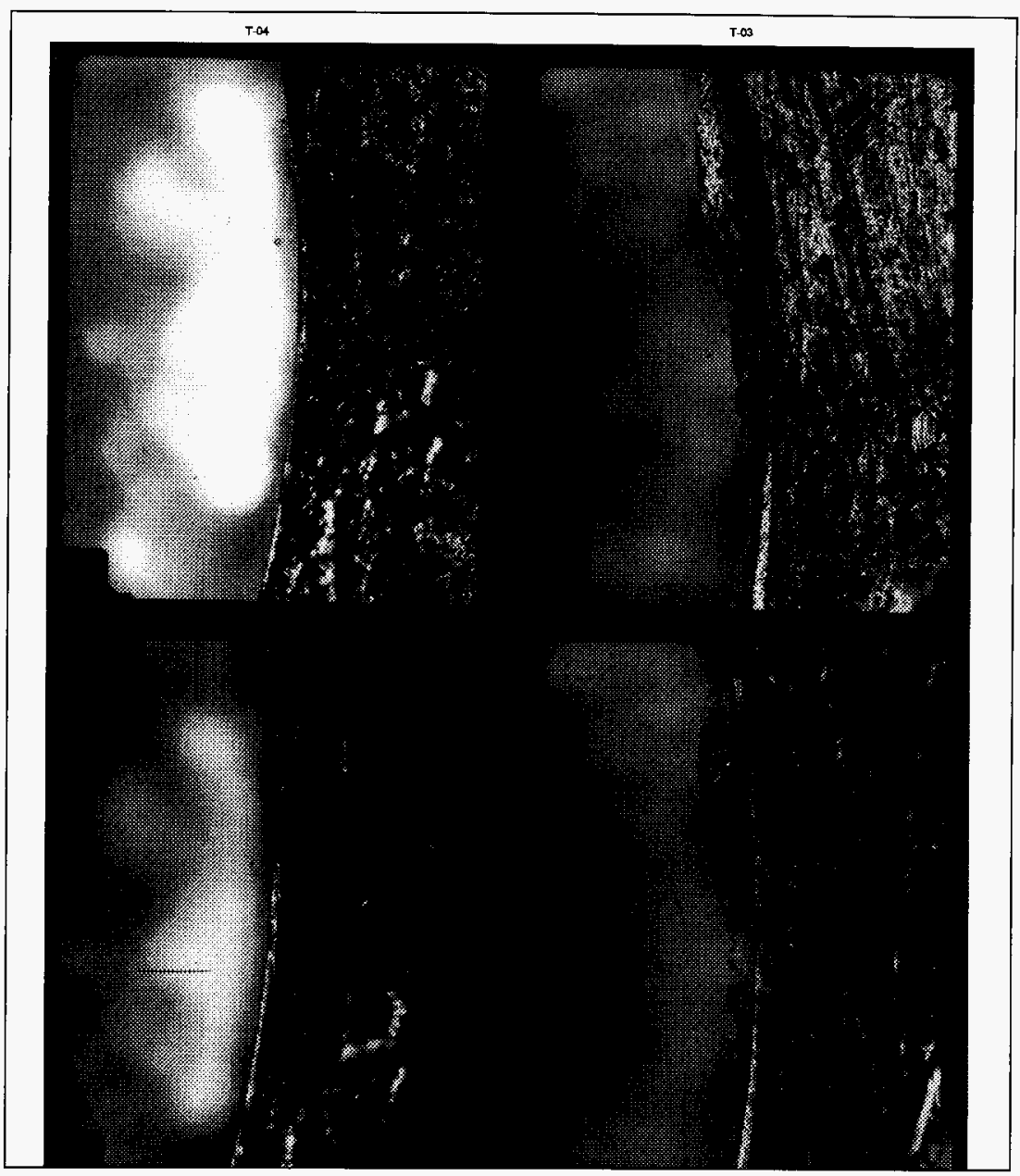

Figure 15. Test \#2 coupon " $T$ " at 100x mag. for two areas (right and left columns) shown in Figure 5. The top row shows braze interface areas, T-04 and T-03, prior to the 17 day chemical/radiation exposure while the bottom row shows the same areas after the 17 day exposure. 
WHC-SD-WM-TRP-268, Rev. 0

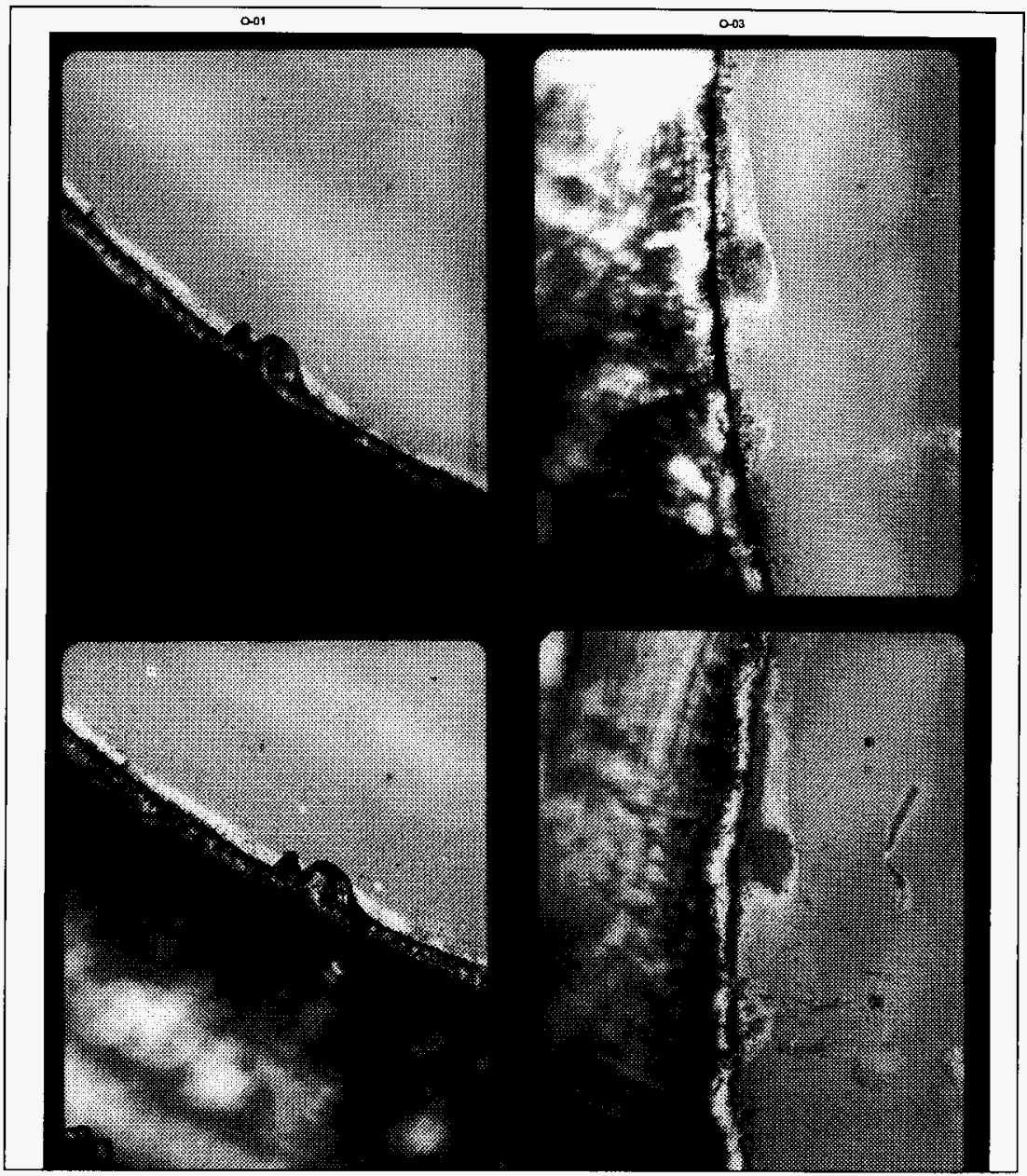

Figure 16. Test \#2 coupon " $\mathrm{O}$ " at $100 \mathrm{x}$ mag. for two areas (right and left columns) shown in Figure 6. The top row shows braze interface areas, $\mathrm{O}-01$ and $\mathrm{O}-03$, prior to the 17 day chemical/radiation exposure while the bottom row shows the same areas after the 17 day exposure 
WHC-SD-WM-TRP-268, Rev. 0

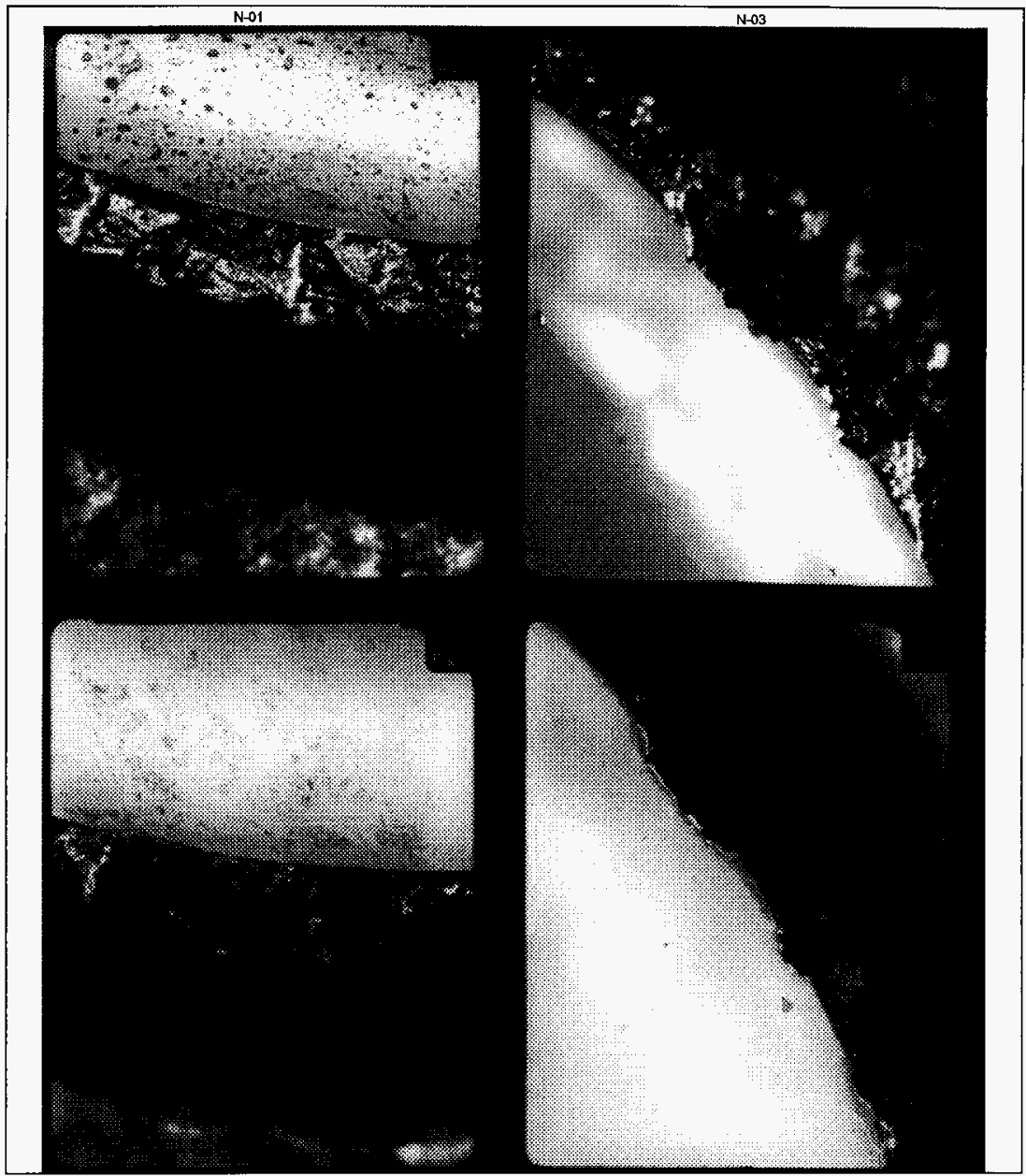

Figure 17. Test \#2 coupon "N" at 100x mag. for two areas (right and left columns) shown in Figure 6 . The top row shows braze interface areas, $\mathrm{N}-01$ and $\mathrm{N}-03$, prior to the 17 day chemical/radiation exposure while the bottom row shows the same areas after the 17 day exposure. 
WHC-SD-WM-TRP-268, Rev. 0

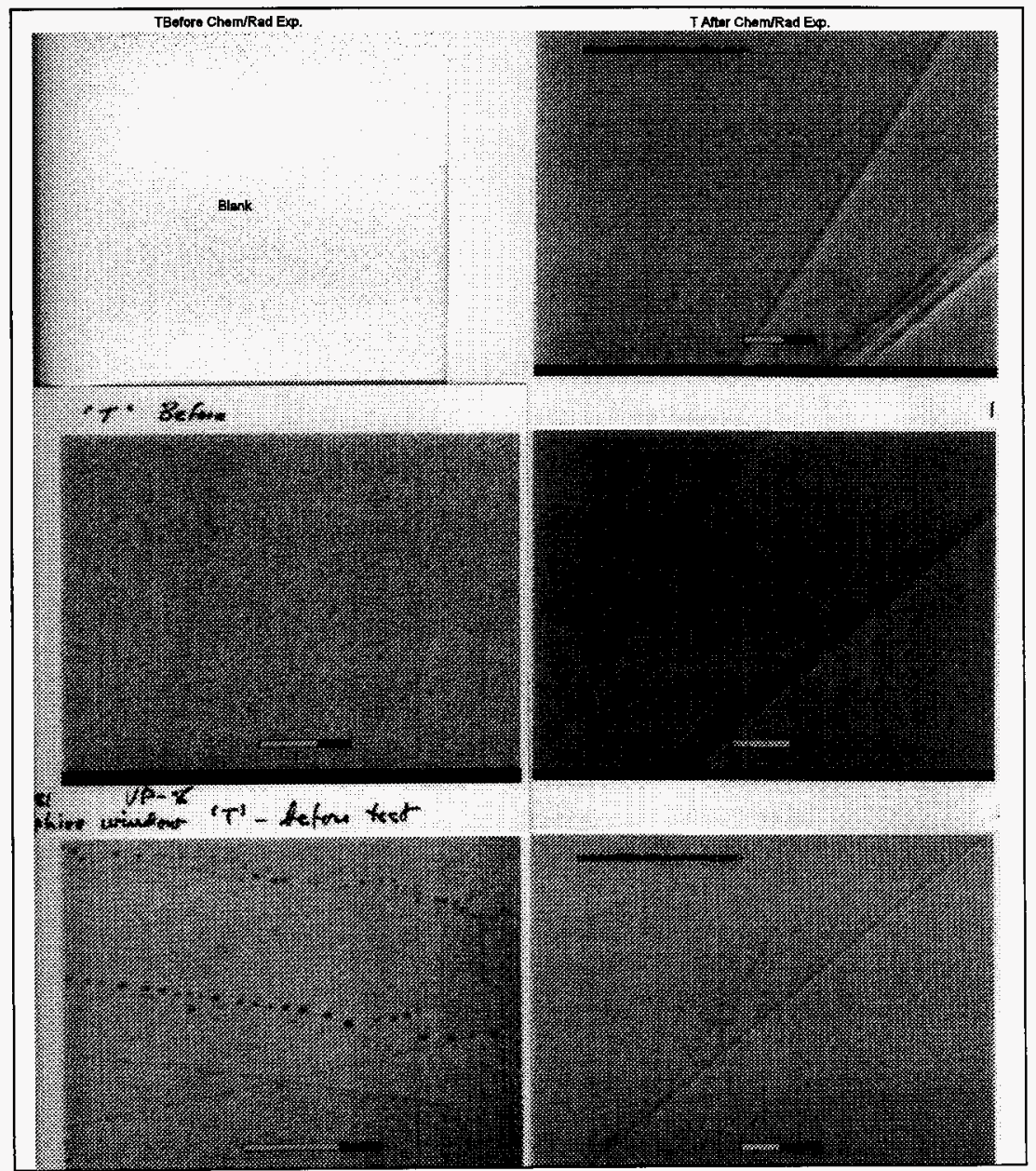

Figure 18. SEM of sapphire window surface for "T". The left column is prior to the 17 day radiation/chemical exposure while the right column is after the exposure. Scale (clear rectangle) on photos: top right-1 miron, middle row-5 micron, left bottom-50 micron, \& right bottom- 20 micron. 
WHC-SD-WM-TRP-268, Rev. 0

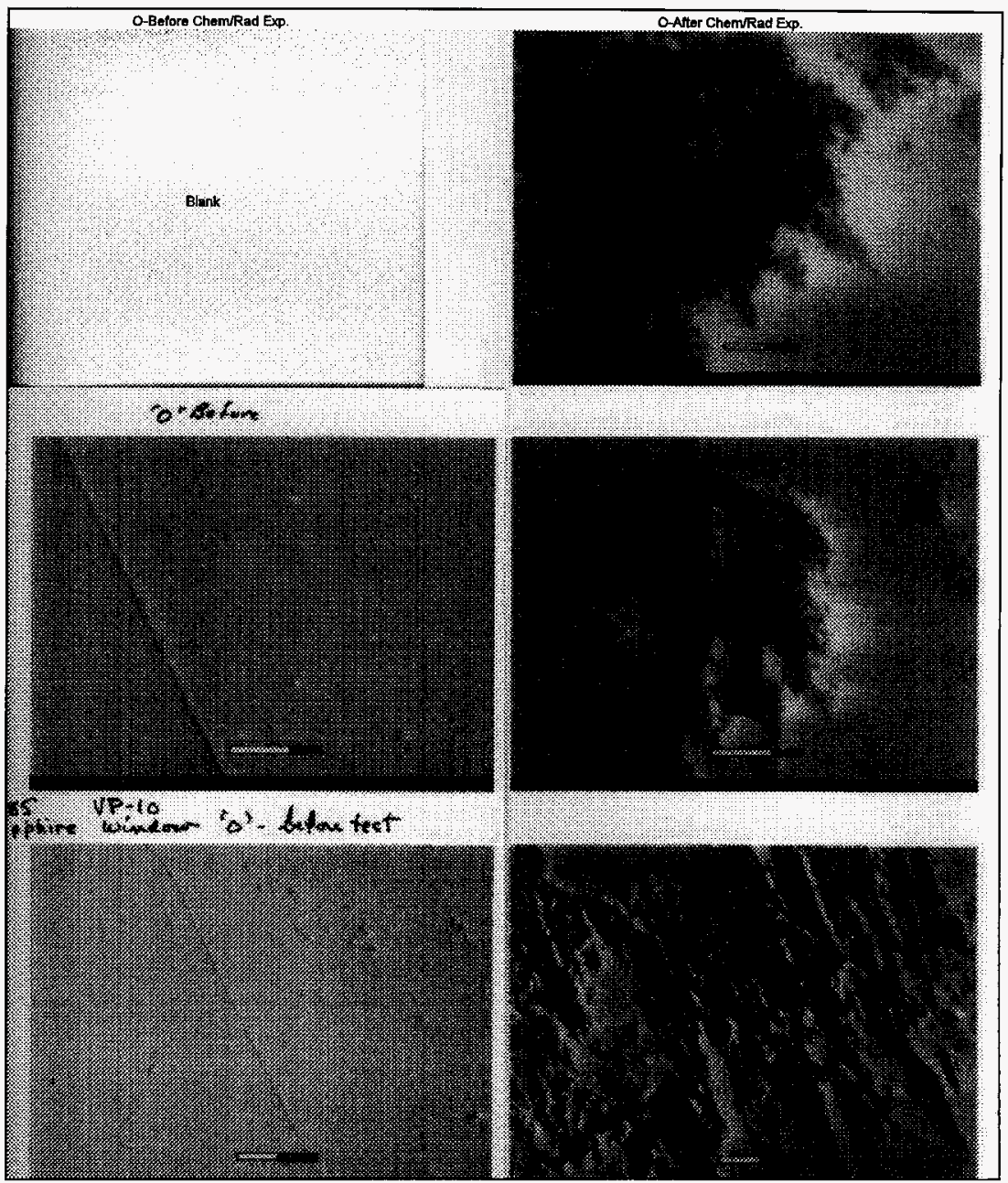

Figure 19. SEM of sapphire window surface for "O". The left column is prior to the 17 day radiation /chemical exposure while the right column is after the exposure. Scale (clear rectangles) on photos: top- 1 micron, middle- 5 micron, \& bottom- 20 micron. 
WHC-SD-WM-TRP-268, Rev. 0

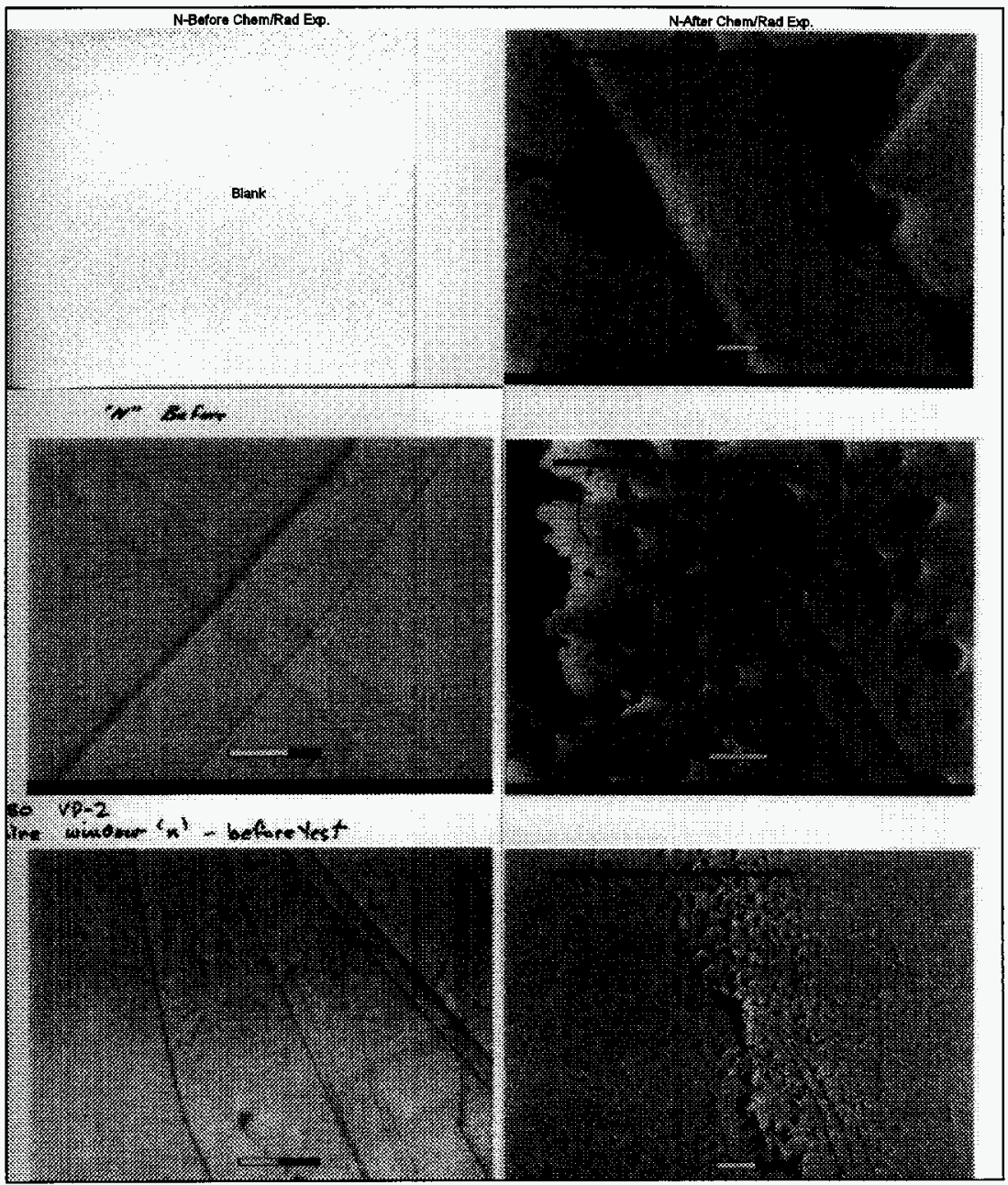

Figure 20. SEM of sapphire window surface for "N". The left column is prior to the 17 day radiation/chemical exposure while the right column is after the exposure. Scale (clear rectangles) on photos: top- 1 micron, middle- 5 micron, and bottom- 20 micron. 


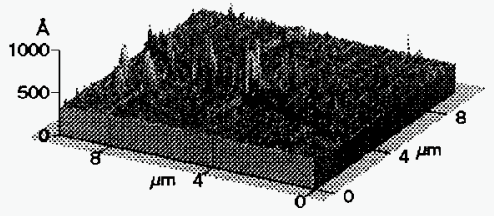

Figure 21a. EFM of sapphire window surface for " $Q$ " exposure. Scale: 1000 angstrons

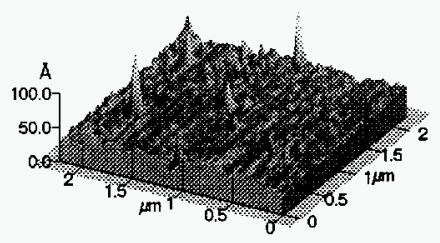

Figure 21c. EFM of sapphire window surface for " $O$ " - Before 17 day chemical /radiation exposure. Scale: 100 angstroms.

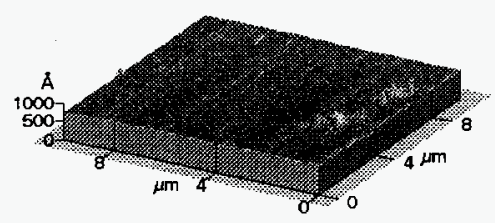

Figure 21b. EFM of sapphire window surface for "Q" - After 17 day chemical /radiation exposure. Scale: 1000 angstroms.

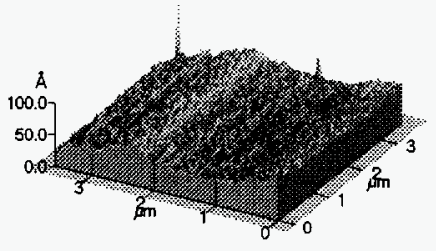

Figure 21d. EFM of sapphire window surface for "O" - After 17 day chemical /radiation exposure. Scale: 100 angstroms. 

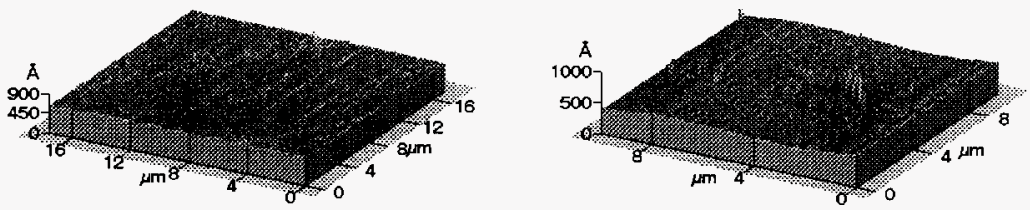

Figure 22a. EFM of sapphire window surface for " $\mathrm{N}$ " - Before 17 day chemical/radiation exposure Scale; 900 angstroms.

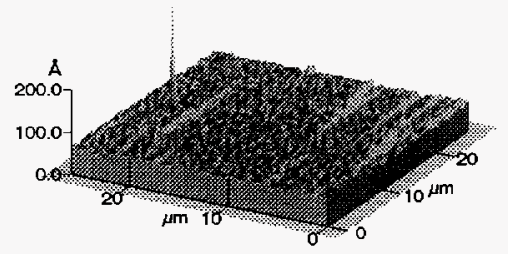

Figure 22c. EFM of sapphire window surface for "N" - Before 17 day chemical/radiation exposure. Scale: 200 angstroms.
Figure 22b. EFM of sapphire window surface for " $\mathrm{N}$ " - After 17 day chemical/radiation exposure Scalej 1000 angstroms.

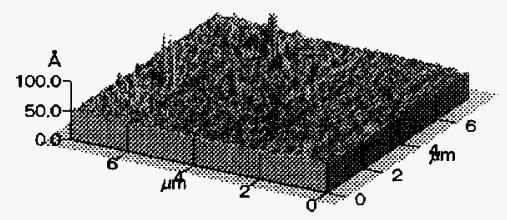

Figure 22d. EFM of sapphire window surface for " $\mathrm{N}$ " - After 17 day chemical/radiation exposure. Scale: 100 angstroms. 
WHC-SD-WM-TRP-268, Rev. 0

\section{APPENDIX A}

Raman Spectroscopic Cone Penetrometer

A-1 
Appendix A

The Raman Spectroscopic Cone Penetrometer would have a probe with a long fiber optic cable connection that is deployed into the tank, as shown in Figure A-1 below. The fiber optic probe must be capable of handling the environment created by the radioactive, caustic waste, as well as the physical environment from the Cone Penetrometer activities. The Raman laser and the spectrometer would be outside the harsh tank environment in a protective shelter, but would still be exposed the blowing dust and other factors of an outdoor operating environment. Instrumentation and control hardware and software will be provided to remotely operate and control all system equipment. The trailer containing this equipment potentially may be located from 150 to up to 900 feet from the cone penetrometer, outside the tank farm perimeter fence.

Hanford Site Outdoor Environment

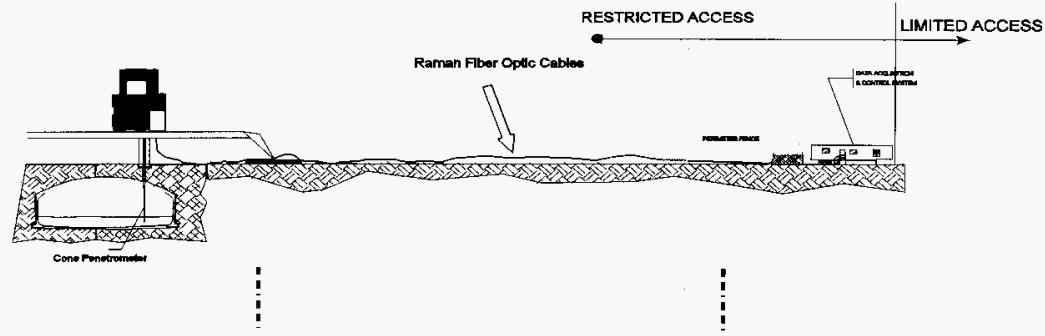

Figure A-1. Cone penetrometer system deployed over an underground waste tank.

Table A-I defines a number of physical parameters covering the anticipated range of environmental conditions anticipated within the Hanford tanks while Table A-II shows an example of the chemical environment an in situ probe would experience in a waste tank (Ref 1 and 2). Although all values and ranges are approximate, this data provides some typical information of the environment in which an in-situ Raman cone penetrometer fiber optic probe would need to function. In general, these physical environment and the list of waste chemical composition below can be applied to most of the waste tanks on the Hanford Site. 
Table A-I

In-Tank Environmental Parameters

Temperature:

Pressure:

Radiation flux:

- Radiation:

Relative Humidity: Moisture Content:

Specific Gravity:

Corrosivity:

Condens liquids solids - $65^{\circ}-190^{\circ} \mathrm{F}$

$-2.5^{\prime \prime}$ to +1 " $\mathrm{H}_{2} \mathrm{O}$ (during gas release events, measured in head space)

Up to $10.5 \mathrm{E}+3 \mathrm{R} / \mathrm{hr}$ within the waste

$10 \%-100 \%$ (head space)

$>20 \%$ for solid waste

1.2 to 2.0 for solid or liquid waste

nsed vapors - $\mathrm{pH}$ from 8 to 14

$\mathrm{pH}$ from 8 to 14 , up to $3.56 \mathrm{M} \mathrm{NaOH}$

$\mathrm{pH}$ from 8 to 14 and up to $3.56 \mathrm{M} \mathrm{NaOH}$

Hazardous location:

Class 1, Division 1, Group B per NEC Article 500. 
Table A-II

In-Tank Chemical Parameters for the Anticipated Contents of Tank 101-SY

Solid Sludge Summary:

$\begin{array}{lcc}\text { Chemicals } & \begin{array}{c}\text { Concentrations } \\ \text { molarity (kg/liter) }\end{array} & \text { Probable major mineral phases: } \\ \text { sodium } & 7-16 & \\ \text { nitrate } & 1.5-3 & \begin{array}{c}\text { sodium nitrate } \\ \text { nitrite }\end{array} \\ \text { hydroxide } & 1.3-3.4 & \text { sodium nitrite } \\ \text { aluminum } & 1.2-2.7 & \text { sodium aluminum hydroxide } \\ \text { carbonate } & 0.7-2.5 & \text { sodium carbonate } \\ \text { chloride } & 0.2-0.5 & \\ \text { phosphate } & 0.2-0.4 & \\ \text { sulfate } & 0.06-0.2 & \\ & 0.03 & \\ \text { ToC } & 9-25 \mathrm{~g} / \mathrm{L} & \\ \text { Sr-89/90 } & 6 \times 10^{3}-7 \times 10^{5} \mu \mathrm{Ci} / \mathrm{L} & \\ \text { Tc-99 } & 9 \times 10^{1}-2 \times 10^{2} \mu \mathrm{Ci} / \mathrm{L} & \\ \text { Cs-137 } & 3 \times 10^{5}-7 \times 10^{5} \mu \mathrm{Ci} / \mathrm{L} \\ \text { Pu-239/240 } & 8 \times 10^{\circ}-8 \times 10^{1} \mu \mathrm{Ci} / \mathrm{L} \\ & \end{array}$

Currently, little data exists for physical characterization of single shell tank saltcakes. However, several simulants were developed for temperature envelop testing of a universal core sample drill bit (WHC-SD-WM-TI-545). Although the simulants were designed to emulate the chemical nature of the Single Shell Tanks, only major chemical components were used in the synthetic formulation.

The physical data for a BY-104 salt cake simulant, shown in Table A-III, are typical of those expected with real tank wastes. These parameters are based on tests with several materials, including sulfur $\mathrm{K}$-mag and three synthetic saltcake materials, that were examined in the temperature envelope testing of a universal core sample drill bit. The BY-104 salt cake simulant (developed to simulate conditions in Tank 241-BY-104) data shown in Table A-III, is the most chemically representative of all the simulants 
WHC-SD-WM-TRP-268, Rev. 0

examined. Although the effects of tank aging with crystal growth, as well as additional minor component chemical impurities are not accounted for and all organics, heavy metals, and radionuclides have been omitted to simplify waste disposal requirements and to minimize any potential safety hazards, the test data does provide a good estimate of the physical environment expected with salt cake waste.

\section{Table A-III}

BY-104 Simulant Physical Properties

Bulk Density:

$1.41\left(\mathrm{gm} / \mathrm{cm}^{3}\right)$

Unconfined compression: $3264\left(\mathrm{lb} / \mathrm{in}^{2}\right)$ stress

Direct shear strength: $\quad 459\left(\mathrm{lb} / \mathrm{in}^{2}\right)$ stress

Penetrometer Resistance: $34507\left(\mathrm{lb} / \mathrm{in}^{2}\right)$ resistance

Thermal conductivity: $\quad 1.66\left(\mathrm{~W} / \mathrm{m}^{\star} \mathrm{K}\right)$ at $334^{\circ} \mathrm{K}$ 


\section{APPENDIX B}

Cobalt-60 Gamma Pit Irradiation Facility

B-1 
Appendix B

Cobalt-60 Gamma Pit Irradiation Facility

The gamma pit used in this simulated caustic/radioactive environment test is located in the Hanford 3730 building, 300 Area, and is operated by the Pacific Northwest National Labs (PNNL). The radiation sources are from two clusters of Cobalt 60 capsules, having a total inventory of about $21.9 \mathrm{Kci}$. The radiation flux degradation of these Cobalt 60 is tracked with a computer program which is validated at least once a year with a calibrated radiation dosimeter. The Cobalt 60 capsules are located at the bottom of a 7 foot diameter, $13 \mathrm{ft} 8$ in deep stainless steel caisson that is filled with water. The water provides personnel radiation shielding and a means for temperature control.

Access to the radiation is through irradiation tubes ( 1.8 to 6 in diameter) which are sealed on the bottom (dry test environment) and extend down into the caisson in close proximity to the Cobalt sources. The radiation level a sample will experience is dependent on the location of a tube and the samples elevation within the tube. Figure B-1 shows the gamma dose rate profile for the tube used in this Raman cone penetrometer test.

The actual dose levels experienced by the cone penetrometer components varied because of their different elevation within the test fixture. Loose optical components were placed in the bottom of an outer container while a cone penetrometer head mounted sapphire window was in the simulant bath about 2 inches higher in the irradiation tube. This produced a variation in exposure between 


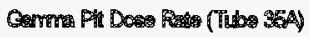

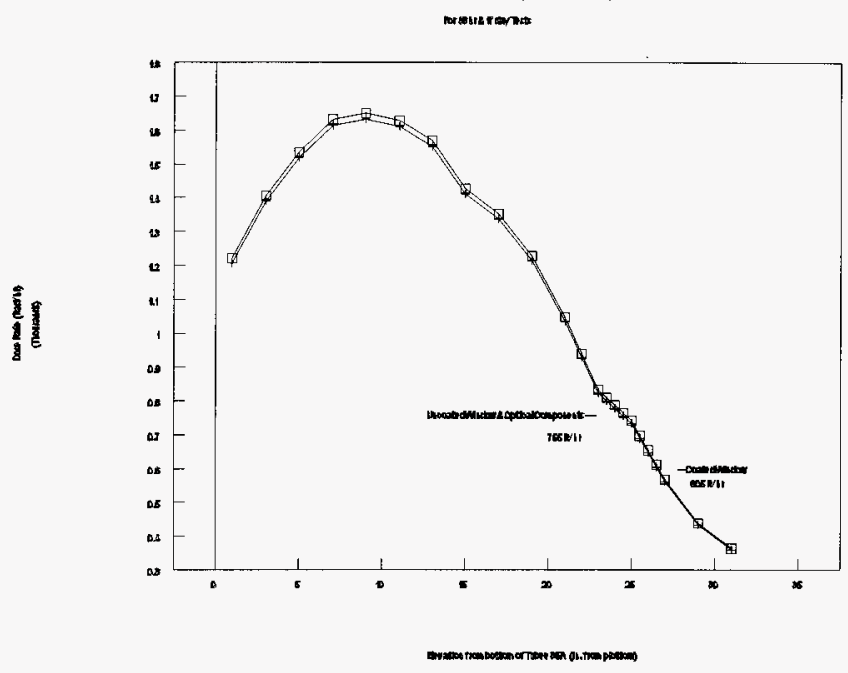

Figure B-1. Gamma dose rate profile for tube $35 \mathrm{~A}$ of the Hanford 3730 gamma pit irradiation facility operated by PNNL. 


\section{DISTRIBUTION SHEET}

\begin{tabular}{|c|c|c|c|c|c|}
\hline \multirow{2}{*}{$\begin{array}{l}\text { To } \\
\text { Remote System and Sensor } \\
\text { Applications }\end{array}$} & \multirow{2}{*}{\multicolumn{3}{|c|}{$\begin{array}{l}\text { From } \\
\text { Remote System and Sensor } \\
\text { Applications }\end{array}$}} & \multicolumn{2}{|l|}{ Page 1 of 1} \\
\hline & & & & \multicolumn{2}{|c|}{ Date $9 / 26 / 96$} \\
\hline \multirow{2}{*}{\multicolumn{4}{|c|}{$\begin{array}{l}\text { Project Title/Work Order } \\
\text { WHC-SD-WM-TRP-268, Rev. 0, "Summary of Raman Cone Penetrometer } \\
\text { Probe Waste Tank Radiation and Chemical Environment Test" }\end{array}$}} & \multirow{2}{*}{\multicolumn{2}{|c|}{$\begin{array}{l}\text { EDT No. } 618422 \\
\text { ECN No. }\end{array}$}} \\
\hline & & & & & \\
\hline Name & MSIN & $\begin{array}{l}\text { Text } \\
\text { With All } \\
\text { Attach. }\end{array}$ & Text Only & $\begin{array}{l}\text { Attach./ } \\
\text { Appendix } \\
\text { Only }\end{array}$ & $\begin{array}{c}\text { EDT/ECN } \\
\text { Only }\end{array}$ \\
\hline $\begin{array}{l}\text { R. Akita } \\
\text { G. N. Boechler } \\
\text { D. A. Brown } \\
\text { R. J. Cash } \\
\text { D. A. Dodd } \\
\text { J. G. Douglas } \\
\text { J. B. Duncan } \\
\text { P. R. Hernandez } \\
\text { J. A. Hunter } \\
\text { C. E. Hanson } \\
\text { J. S. Hartman } \\
\text { J. R. Jewett } \\
\text { A. F. Noonan } \\
\text { F. R. Reich (16) } \\
\text { D. A. Reynolds } \\
\text { Central Files (original +2) } \\
\text { EDMC }\end{array}$ & $\begin{array}{l}\text { T6-20 } \\
H 5-09 \\
\text { K8-50 } \\
\text { S7-15 } \\
\text { T6-50 } \\
\text { L5-55 } \\
\text { L5-55 } \\
\text { S7-54 } \\
\text { L5-31 } \\
\text { H5-09 } \\
\text { K5-25 } \\
\text { T6-09 } \\
\text { K9-91 } \\
\text { L5-55 } \\
\text { R2-11 } \\
\text { A3-88 } \\
\text { H6-08 }\end{array}$ & $\begin{array}{l}X \\
X \\
X \\
X \\
X \\
X \\
X \\
X \\
X \\
X \\
X \\
X \\
X \\
X \\
X \\
X \\
X\end{array}$ & & . & \\
\hline Tank Farm Information Center & $\mathrm{Rl}-20$ & $x$ & & & \\
\hline
\end{tabular}

